\title{
microRNAs and Their Roles in Plant Development
}

\author{
Qingkun Dong ${ }^{1}$, Binbin $\mathrm{Hu}^{1,2}$ and Cui Zhang ${ }^{1,2 *}$ \\ ${ }^{1}$ Key Laboratory of Plant Molecular Physiology, CAS Center for Excellence in Molecular Plant Sciences, Institute of Botany, Chinese \\ Academy of Sciences, Beijing, China, ${ }^{2}$ College of Life Sciences, University of Chinese Academy of Sciences, Beijing, China
}

Small RNAs are short non-coding RNAs with a length ranging between 20 and 24 nucleotides. Of these, microRNAs (miRNAs) play a distinct role in plant development. miRNAs control target gene expression at the post-transcriptional level, either through direct cleavage or inhibition of translation. miRNAs participate in nearly all the developmental processes in plants, such as juvenile-to-adult transition, shoot apical meristem development, leaf morphogenesis, floral organ formation, and flowering time determination. This review summarizes the research progress in miRNA-mediated gene regulation and its role in plant development, to provide the basis for further in-depth exploration regarding the function of miRNAs and the elucidation of the molecular mechanism underlying the interaction of miRNAs and other pathways.

\section{OPEN ACCESS}

Edited by:

Xigang Liu,

Hebei Normal University, China

Reviewed by: Guodong Ren,

Fudan University, China Stephen Jackson, University of Warwick,

United Kingdom

${ }^{*}$ Correspondence:

Cui Zhang

cuizhang@ibcas.ac.cn

Specialty section:

This article was submitted to Plant Physiology,

a section of the journal

Frontiers in Plant Science

Received: 29 November 2021 Accepted: 27 January 2022 Published: 18 February 2022

Citation:

Dong Q, Hu B and Zhang C (2022) microRNAs and Their Roles in Plant

Development.

Front. Plant Sci. 13:824240. doi: 10.3389/fp/s.2022.824240
Keywords: microRNA, plant development, microRNA movement, hormone, crop yield

\section{INTRODUCTION}

RNA is one of the four major macromolecules of life and is essential in the regulation and expression of genes. RNA can be divided into two groups: coding and non-coding RNAs. In plants, $24 \mathrm{nt}$ small interfering RNAs (siRNA) and $21 \mathrm{nt}$ microRNAs (miRNA) have the highest expression abundance of small non-coding RNAs. siRNAs were first discovered in plants and are involved in the transcriptional gene silencing and post-transcriptional gene silencing (PTGS) pathway in plants (Hamilton and Baulcombe, 1999; Sijen et al., 2001; Pal-Bhadra et al., 2002) and RNA interfering pathway in animals (Elbashir et al., 2001).

miRNAs were first identified from nematodes (Caenorhabditis elegans) by Victor Ambros lab in collaboration with Gary Ruvkun lab, who confirmed that a miRNA (Lin-4) has a role in regulating the temporal developmental of nematode larvae (Lee et al., 1993; Wightman et al., 1993; Fire et al., 1998; Stricklin et al., 2005). Since then, miRNAs have been reported in Drosophila, nematodes, mammals, and plants. In plants, $22 \mathrm{nt}$ miRNA is able to cut the target mRNA and the cleavage product can be further processed by RNA-DEPENDENT RNA POLYMERASE 6 (RDR6) and DICER-LIKE 4 to produce secondary 21 nt siRNA. In addition, the symmetric miRNA/miRNA* can be processed by DCL2 and generate secondary $22 \mathrm{nt}$ miRNAs. These siRNAs are called phased siRNAs (PhasiRNAs) because they are the endogenous plant siRNAs with phase arrangement structure characteristics (Borges and Martienssen, 2015). PhasiRNA can be divided into cis-acting siRNA and trans-acting siRNA (ta-siRNA; Chen et al., 2010; Zhai et al., 2011; Arikit et al., 2014; Deng et al., 2018).

miRNAs are demonstrated to be vital in plant development. They are usually transcribed by RNA Polymerase II (Pol II) into pri-miRNAs. These pri-miRNAs are cleaved by a class of RNase-III nucleases called Dicer-like proteins, after which they combine with ARGONAUTE 
(AGO) family proteins to form the RNA-induced silencing complexes (RISCs). RISCs are then involved in the expression and regulation of target genes (Song et al., 2019). miRNAs act in the regulation of meristem characteristics, leaf polarity, flowering patterns. etc. Mutations in miRNA transcription or processing complexes usually have multiple effects on plant from and function, indicating that miRNAs are important to coordinate plant development. For example, the roles of HD-ZIP III-miR165/166 pathway are important in the development of vascular, meristem, and leaf polarity, and the roles of miR156/ miR172 are important in flowering time and flower pattern (D’Ario et al., 2017; Ramachandran et al., 2017; Du et al., 2020; Ma et al., 2020; Lian et al., 2021; Yadav et al., 2021). During plant development, endogenous miRNAs play an important role in gene regulation by targeting related target genes. Several miRNAs function through interactions with hormones. Many components in hormone signaling are targets of miRNAs, and the interactions of these components and the miRNAs enable plants to regulate their growth, development, and differentiation rapidly and effectively. This signaling is done by selecting miRNAs as intermediates to control hormone responses or, conversely, by using hormones to regulate specific miRNA levels (Jodder, 2020; Li et al., 2020; Yu and Wang, 2020). There is evidence indicating that miRNAs can diffuse in tissues as inhibitor signals, so they play an elaborate role in tissue differentiation (Chen and Rechavi, 2021). Here we will summarize the role of miRNAs in the aspects of biogenesis, action mechanism, function in specific tissues, interaction with hormones, and movement to understand how they regulate plant development. miRNAs and their targets involved in plant development are listed in Table $\mathbf{1 .}$

\section{BIOSYNTHESIS AND ACTION MECHANISM OF miRNAS IN PLANTS}

Most of miRNAs are a kind of conserved endogenous small RNA, which plays an important regulatory role after eukaryotic gene transcription (Rodriguez et al., 2010). Most metazoan miRNA genes exist in thousands of introns or exons, whereas plant miRNA genes exist between genes. In addition to this, the secondary structures and lengths of miRNA are greatly different among plant species (Voinnet, 2009). Animal miRNAs exist in clusters along the genome, and they can be co-transcribed in the form of poly-cistrons (Ha and Kim, 2014). In contrast, plant miRNA genes are rarely arranged in series (Kim, 2005; Zhang et al., 2008). Like protein-coding genes, miRNAs start by being transcribed in the nucleus by Pol II to form pri-miRNAs, which range in length from several hundred to several thousand nucleotides and have a $5^{\prime}$ cap and a $3^{\prime}$ poly-A tail (JonesRhoades and Bartel, 2004; Lee et al., 2004; Jones-Rhoades et al., 2006). Under the action of DCL1, pri-miRNAs are cleaved into pre-miRNAs, which are $\sim 70 \mathrm{nt}-350 \mathrm{nt}$. These pre-miRNAs are further formed by the interaction of the DCL1 enzyme, RNA-binding protein HYL1 (Hyponastic Leaves 1), and $\mathrm{C} 2 \mathrm{H} 2$ zinc finger protein SE (Serrate) on pre-miRNA (Kurihara and Watanabe, 2004; Jones-Rhoades et al., 2006) into mature miRNAs. The mature miRNAs have 2 bases protruding at the $3^{\prime}$ end (miRNA double-stranded complex). This miRNA complex is methylated at the $2^{\prime}-\mathrm{OH}$ position of its $3^{\prime}$ end under the action of HUAENHANCER1 protein to prevent degradation (Li et al., 2005). Most of the methylated miRNA complexes are transported into the cytoplasm with the help of plant homolog of exportin-5, HASTY (HST; Park et al., 2005; Brioudes et al., 2021). The RNA-induced RISC, generated by miRNA, is eventually produced in the cytoplasm (Park et al., 2005; Jones-Rhoades et al., 2006). Recent studies showed that RISC can be assembled in the nucleus and exported to the cytosol by EXPO1 (Bologna et al., 2018), and HST also regulates pri-miRNA transcription and processing (Cambiagno et al., 2021). In the RISC complex, the AGO protein is the most important structural protein. It contains four domains: the N-terminal domain (N), the PIWI/ Argonaute/Zwille (PAZ) domain, the MID domain, and the P-element-induced wimpy tested (PIWI) domain. The PAZ domain can bind to RNA and the PIWI domain with RNase $\mathrm{H}$ activity. 10 different types of AGO proteins have been found in Arabidopsis thaliana; most of them contain catalytic reaction residues. Of these different AGO proteins, ARGONAUTE1 (AGO1; Baumberger and Baulcombe, 2005; Qi et al., 2005), AGO2 (Carbonell et al., 2012), AGO4 (Qi et al., 2006), AGO7 (Montgomery et al., 2008), and AGO10 (Ji et al., 2011; Zhu et al., 2011) have been demonstrated in the gene silencing pathway of target RNAs. AGO1 protein is involved in PTGS as the main component of RISC that binds to a short guide RNA such as miRNA or siRNA. AGO4 and AGO6 are mainly involved in the repeat-associated siRNA pathway, and AGO7 plays a role in the formation of ta-siRNA (Vaucheret, 2008; Duan et al., 2015; Singh et al., 2015; Fang and Qi, 2016).

Studies have shown that mature miRNAs inhibit the translation of target genes, regulate the expression of plant genes by complementary pairing with coding region, some binding to $3^{\prime}$ UTR and 5'UTR of the target mRNA, or regulate the expression of genes by cutting target gene mRNA at the post-transcriptional level. This inhibition by mature miRNAs alters the morphogenesis of plant organs, growth, development, hormone secretion, signal transduction, and the ability of plants to respond to external stress and environmental factors (Liu et al., 2009a; Yokotani et al., 2009; Naqvi et al., 2012). miRNA in plants is highly complementary to its target mRNA, so its main mode of action is cleavage. The translation inhibition pathways in plants have only been found in recent years. The cleavage and inhibition mechanisms are mostly coordinated depending on the complementarity between miRNAs and their targets (Brodersen et al., 2008; Yu et al., 2017; O’Brien et al., 2018).

\section{THE FUNCTION OF miRNAs IN PLANT GROWTH AND DEVELOPMENT}

The regulation of plant growth and development is very precise and is influenced by both internal genetic information and the external environmental factors. Normal expression of miRNAs is necessary for the growth and development of plants. Previous studies have shown that miRNA widely regulates plant growth and development. 
TABLE 1 | miRNAs, the targets, and their roles in plant development.

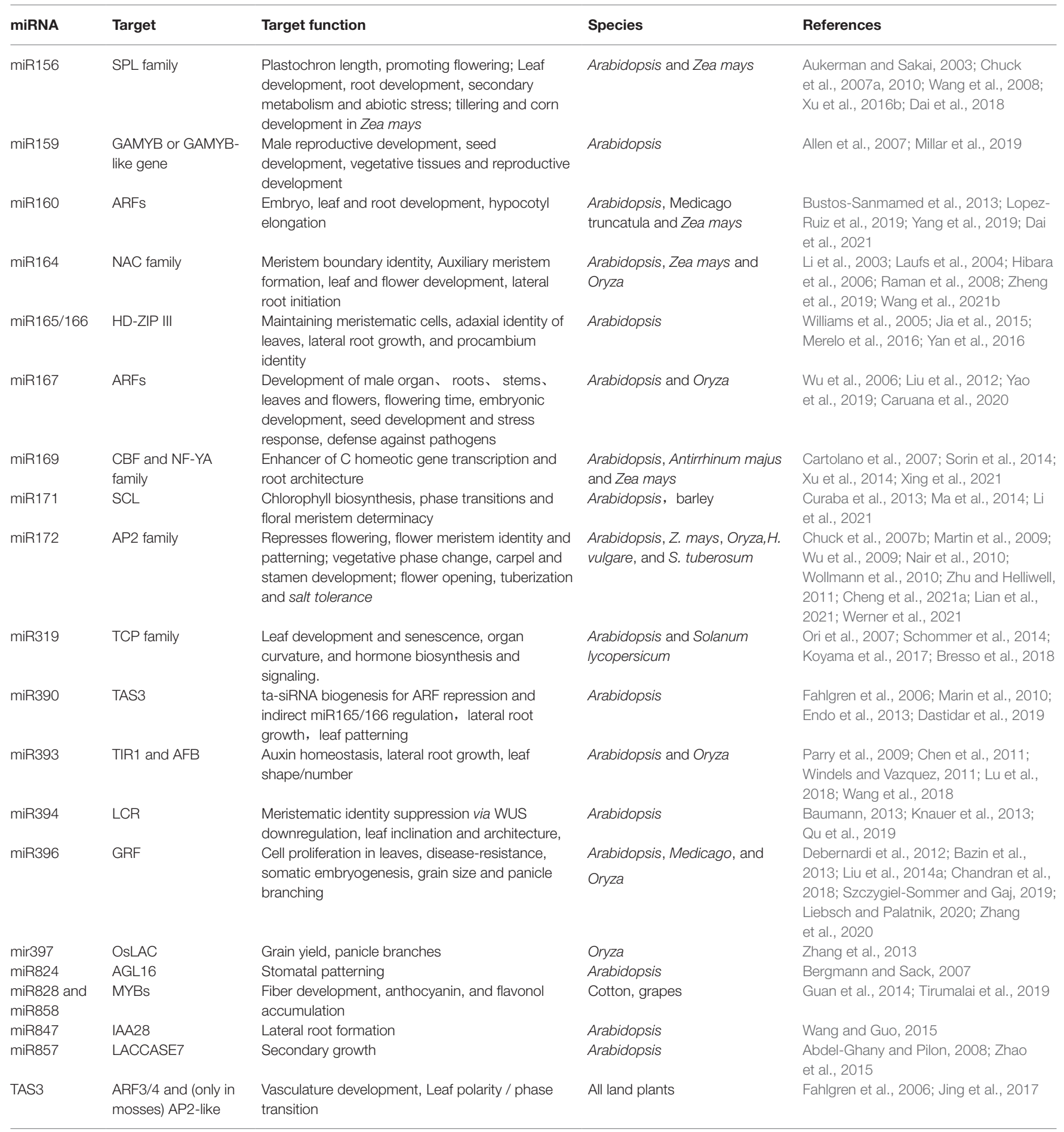

The Role of miRNAs in the Shoot Meristem Unlike animals, plants can continuously produce new organs throughout their life cycle. Their apical meristem forms in embryo and has a group of stem cells with multidirectional differentiation potential and the ability to self-replicate. During the development of a plant, the shoot apical meristem (SAM) plays a central role in the formation and development of its aboveground organs. The STM (shoot meristemless)-WUS (Wuschel)-CLV (Clavata) pathway plays a key role in the maintenance of meristem activity (Schoof et al., 2000; Gaillochet and Lohmann, 2015; Somssich et al., 2016). To some extent, the same mechanisms are also demonstrated in flower meristems. miRNA plays a central role in the regulation of gene expression networks, orchestrating the establishment and the maintenance 
of the SAM by targeting and regulating multiple genes in the STM-WUS-CLV signaling pathway (Figure 1). miR394 is generated in the L1 layer on the surface of the SAM and diffuses down to the Organizing Center (OC; Figure 1). In the OC, expression of Leaf Curling Responsiveness (LCR) is inhibited (Knauer et al., 2013) and directly results in the downregulation of WUS, a SAM-specific gene (Song et al., 2012). Although the concentration of miR394 in the L1 layer is higher than that in the OC layer, the inhibitory effect of miR394 on LCR only occurs in OC, implying that an exact concentration of miR394 is of great importance to its function in A. thaliana (Knauer et al., 2013). Meanwhile, there are diversified functions for stem cell regulation mediated by miR394-LCR (Kumar et al., 2019). AGO10 can specifically bind to miR165/166 and ultimately promote the expression of HD-ZIP III. HD-ZIP III is an important transcription factor family that regulates SAM in A. thaliana and is a target of miR165/166. When miR166/165 does not bind to AGO10 or the AGO10 gene is knocked out, the meristematic tissue of plants is destroyed. AGO1 antagonizes AGO10 in the binding of miR166/165. When miR166/165 binds to AGO1, plants will decrease the expression of the HD-ZIP III genes and terminate SAM development. Recent studies indicate that the interaction between AGO10 and miR165/166 depends solely on the structure of miR165/166 and is independent of the catalytic activity of AGO10 (Zhu et al., 2011).

\section{The Role of miRNAs in Leaf Development}

Leaf development includes the differentiation of leaf primordium from the SAM and the subsequent development of leaf blades. In these processes, various regulatory factors are involved. Organogenesis in the SAM is determined by the distribution and polar transport of auxin (Veit, 2009). The target genes of miR160, namely ARF10, ARF16, and ARF17 in the auxin response factors (ARF) family affect leaf development by regulating auxin response. Mutants arf10 and arf17 of $A$. thaliana which are resistant to miR160 cleavage, have an abnormal number of cotyledons, and the edge of the leaves was serrated and curled upward (Liu et al., 2007). At the same time, leaf genesis is regulated by several transcription factors, such as the expression of MYB DOMAIN PROTEIN $(M Y B)$ transcription factor, in leaf primordium. These specific ASYMMETRIC LEAVES1/ROUGH SHEATH2/PHANTASTICA gene families can be used as a transcription suppressor to turn off the meristematic specific gene KNOX1 to promote growth and differentiation (Hay et al., 2004; Piazza et al., 2005). In the process of establishing dorsal-ventral polarity in plant leaves, expression of HD-ZIP III and the MYB protein ASYMMETRIC LEAVES1 are the determinants of the ventral axis, while expression of KANADI (KAN), ARF3, and ARF4 determine the fate of the dorsal axis. The YABBY gene acts downstream of the KAN gene in A. thaliana and is a decisive gene for leaf dorsal development. The function of HD-ZIP III genes in leaf polarization is relatively clear (Figure 2). The expression of HD-ZIP III was maintained only on the adaxial side, as members of HD-ZIP III family, are inhibited by miR165/166 on the abaxial side (Zhong and Ye, 2004).

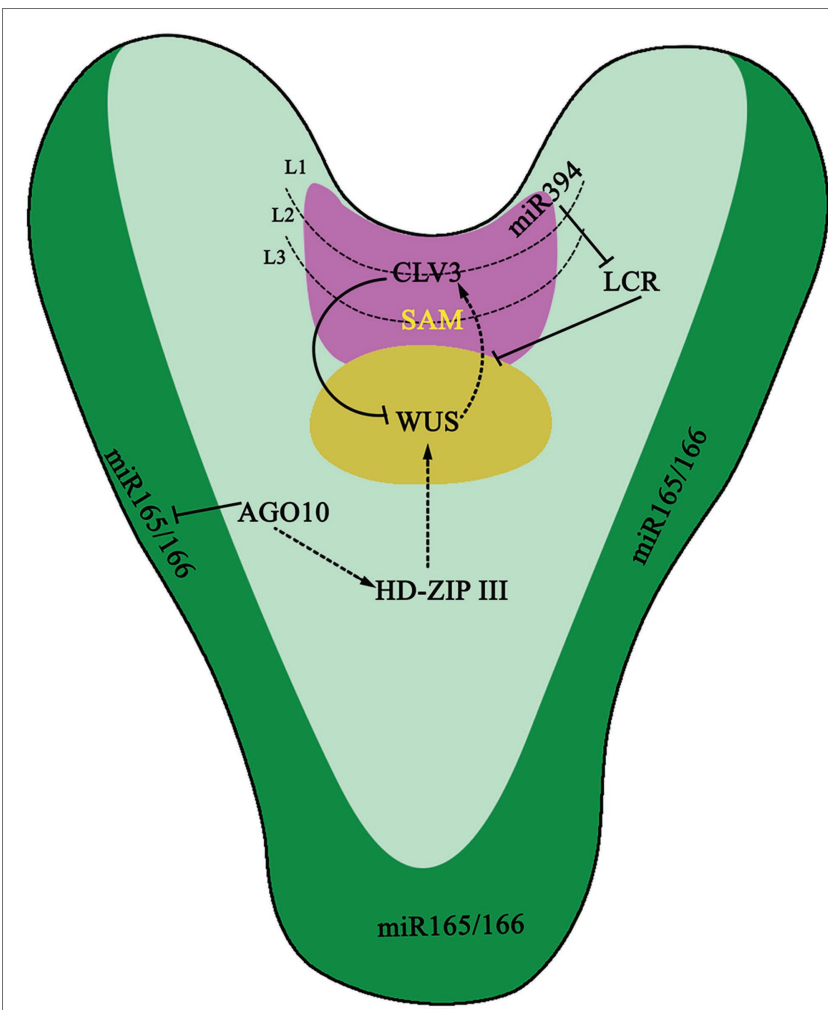

FIGURE 1 | The function of miRNAs in embryo. miR394 expresses in the L1 layer of shoot apical meristem (SAM) and then moves to L3 layer to target Leaf Curling Responsiveness (LCR) gene. LCR further regulates CLAVATAWUSCHEL (CLV-WUS) negative feedback loop for proper SAM development and specification. ARGONAUTE10 (AGO10) specifically sequesters miR166/165 to upregulate Class III homeodomain leucine zipper transcription factors (HD-ZIP III TFs) to maintain SAM development. The dotted arrows represent a proposed positive regulation, whereas lines with perpendicular end bars indicate negative regulation.

AGO1 is necessary for targeting miR165/166 to HD-ZIP III transcripts in leaves and is required for miR165/166 to regulate and restrict PHBOLUSA (PHB) to the adaxial side (Kidner and Martienssen, 2004). Like AGO1, the localization of AGO10 on the adaxial side of the leaf is necessary to inhibit the acellular autonomous miR165/166 activity and maintain the accumulation of HD-ZIP III mRNA in this region (Liu et al., 2009c).

At the same time, miR390 and its effector AGO7 are required to be involved in leaf polarization (Figure 2). TAS3 ta-siRNA determines the adaxial side by inhibiting the expression of ARF3 and ARF4 on the abaxial side of leaves (Chitwood et al., 2009). In Zea maize and A. thaliana, the ventral ta-siARF pathway interacts with the dorsal regulatory factors to some extent. Additionally, the ta-siARF pathway is also required to inhibit the expression of miR165/miR166, which allows for the proliferation of HD-ZIP III. Interference with ta-siARF pathway in maize will obviously affect leaf polarity. Wang et al. reported that miR396 also participated in leaf polarity formation by regulating the proliferation of leaf cells by targeting growthregulating factors (GRFs), thus affecting the formation of dorsal-ventral axis polarity in leaves (Wang et al., 2011). 
miRNAs also regulate leaf size and structure. The balance between miR396 and GRFs ultimately controls the number of cells in leaves and regulates the size of the meristem (Kim et al., 2003; Liu et al., 2009b; Rodriguez et al., 2010; Wang et al., 2011; Baucher et al., 2013; Debernardi et al., 2014). In addition, miR396 can also regulate leaf size through targeting basic Helix-Loop-Helix 74 (Debernardi et al., 2012) and CUC2, which is necessary for the formation of the organ primordial boundary. miR319 regulates the growth and development of A. thaliana leaves by degrading the mRNA of the TCP-like transcription factor family which can regulate CUC2 (Palatnik et al., 2007). In addition, CUC2 expression is also regulated by the repressor miR164 (Koyama et al., 2010). The CUC2miR164 system plays a key role in the evolution of composite leaves (Blein et al., 2008).

Meanwhile, miR319-TCP4 controls leaf senescence (Sun et al., 2017). The sequences of miR159 and miR319 are very similar, and the leaves of the miR159a miR159b double mutant are curled upward, indicating that miR159 also works on leaf development (Allen et al., 2007). miR393 and its target genes TRANSPORT INHIBITOR RESPONSE 1 and AUXIN SIGNALING F-BOX PROTEIN 1/2/3 can affect the shape and size of leaves by regulating the auxin response (Chen et al., 2011).

Stomata are special structures in the plant epidermis. miR824 and its target gene Agamous Like 16 (AGL16) are involved in stomatal development. Overexpression of miR824 led to a decrease in stomatal density, similar to agl16 mutant plants. However, when the regulation of miR824 on AGL16 is destroyed, stomatal density will increase (Kutter et al., 2007). In maize, an increase of GLl5 (Glossyl5) activity can increase the number of young leaves and delay the reproductive development. miRl72 can also promote the transformation from young leaves to mature leaves of maize through the negative regulation of GLl5 mRNAs (Lauter et al., 2005). In tomato (Solanum lycopersicum), the LANCEOLATE gene encodes a TCP transcription factor. Its mutation or downregulation can cause compound leaves of plants to become single leaves. miR319 can target the LANCEOLATE ( $L A)$ gene and cause the formation of single leaves from multiple leaflets (Ori et al., 2007). Yanai et al. found that miR319 in tomato affects the differentiation and leaf shape by inhibiting the expression of the SlGA20 oxidase1 gene, which is an enzyme involved in the GA synthesis pathway (Yanai et al., 2011). miR396 of the legume Medicago truncatula negatively regulates the expression of not only six MtGRF genes but also two bHLH79-like target genes and thus influences root growth and mycorrhizal associations (Bazin et al., 2013).

\section{The Role of miRNAs in Vascular Development}

Vascular plants use xylem to transport water and nutrients absorbed by roots upward and the phloem to transport the carbohydrate assimilated by leaves downward. The vascular bundle consists of three neatly arranged tissues: xylem, procambium/cambium, and phloem (Figure 3). In A. thaliana, the HD-ZIP III gene family is strongly expressed in vascular bundles of roots, stems, and leaves. Overexpression of miR165 in

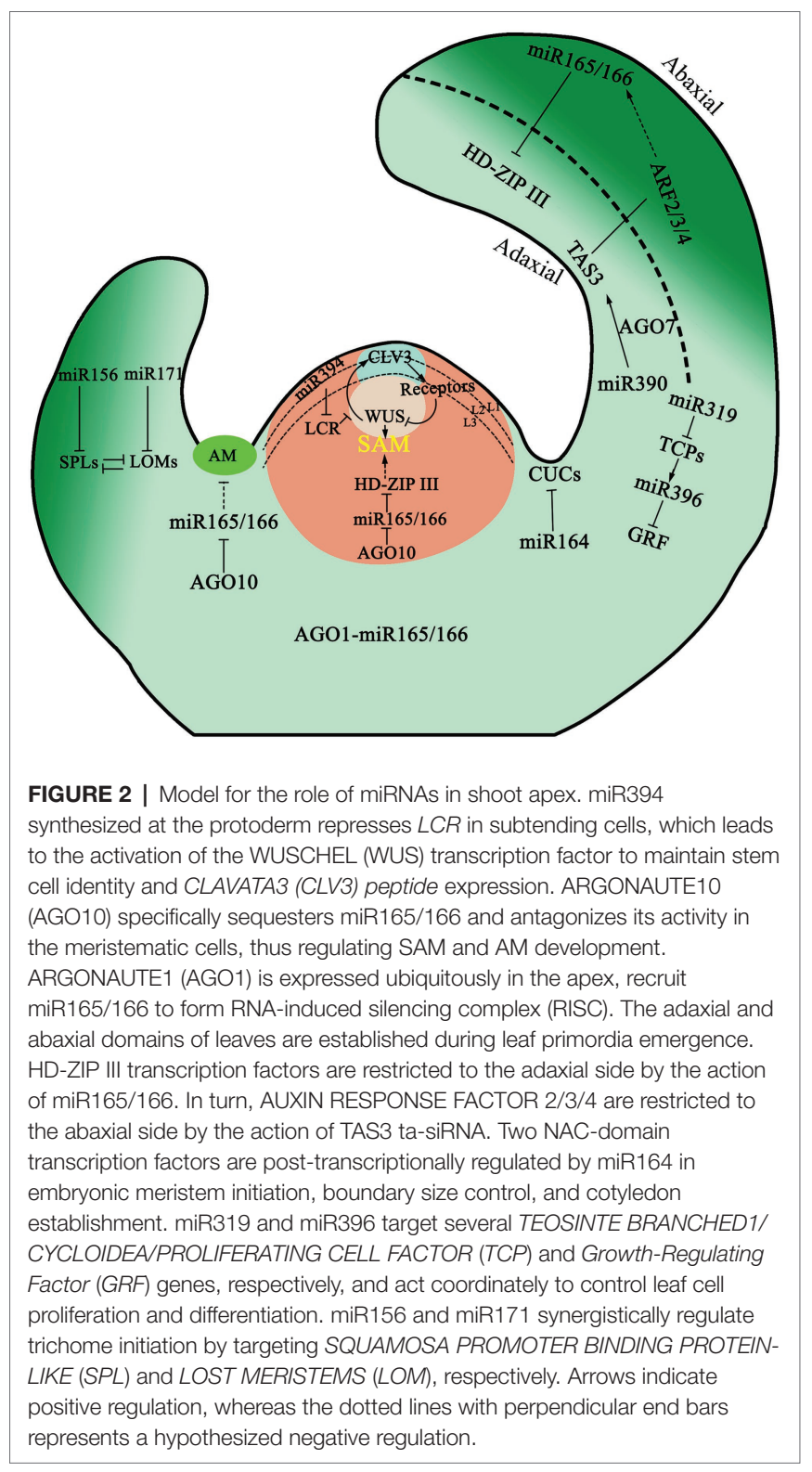

A. thaliana can reduce the transcription level of all members of the HD-ZIP III family, thus regulating the polar differentiation of vascular tissue cells and affecting plant morphogenesis (Zhong and Ye, 1999; Kang and Dengler, 2002; Zhou et al., 2007; Muraro et al., 2014; Du and Wang, 2015; Jia et al., 2015). It was reported that miR166 controls the development of vascular cells and phloem cells by regulating the Homeobox 15 protein (ATHB15) in A. thaliana (Kim et al., 2005). In almost all plant species, it is found that the target site of miR165/166 in class HD-ZIP III genes is highly conserved suggesting that this module is necessary in plant development and evolution (Floyd and Bowman, 2004).

Some miRNAs are also related to cell wall synthesis and fiber development in plants (Kim, 2005). It has been reported that a new miRNA (miR857), is decisive in the formation of secondary walls of vascular in a copper ion-dependent manner. 


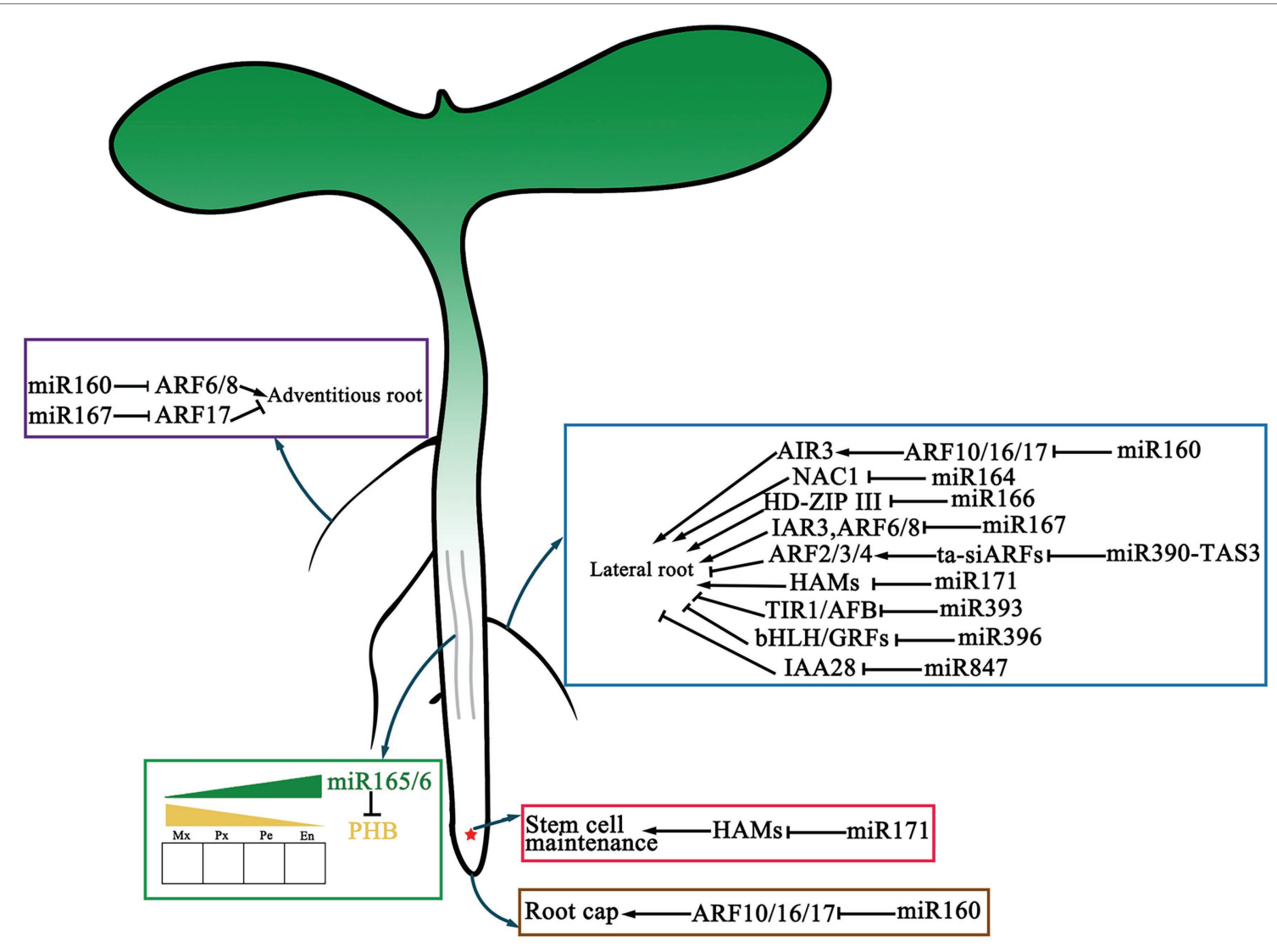

FIGURE 3 | The function of miRNAs in the development of vascular and root. microRNAs are involved in vascular and root development. All of the mRNAs with verified functions in main root, lateral root, adventitious root development as well as their respective main targets are represented. The red asterisk represents the quiescent center (QC). The solid gray line in the middle of the main root represents the vascular tissue.

miR857 regulates the expression of the putative laccase LACCASE7, a member of laccase family of genes, at transcriptional level and affects lignin content (Zhao et al., 2015). A recent study highlighted that some components related to leaf polarity and vascular development, such as miR390, TAS3, and ARF, are conserved across all terrestrial plants. For example, in liverworts, TAS3 ta-siRNA targets ARF as it does in angiosperms (Xia et al., 2017). In Nicotiana tabacum, the semi-dominant phv (phavoluta) mutant without miRl65 regulation has abnormal radial growth of stem and leaf vascular systems, and the vascular tissue of stem nodes is discontinuous, showing that miRl65 controls the growth of vascular cambium suggesting that the function of miR165/166 in vascular development is also conserved in plants (Yu et al., 2005).

\section{The Role of miRNAs in Flower Development}

Flower development is divided into three stages: flowering induction, flowering initiation, and floral organ development. It is a very complicated process involving multiple genes and is also an important event in development of higher plants. Many studies have shown that miRNA plays an important role in flowering.

In $A$. thaliana, the vegetative phase transition is promoted by a group of plant-specific transcription factors (SBP/SPL proteins).
Their expression is inhibited by miR156 and miR157 in the juvenile developmental stage. When the level of miR156/miR157 decreases, the abundance of SBP/SPL proteins increases and the plant changes from vegetative phase to reproductive phase (Xu et al., 2016a; He et al., 2018; Fouracre et al., 2021). miR156 is the main regulatory gene for plant growth cycle transformation, which affects plant phase transformation by targeting SPL (Squamosa Promoter binding protein-Like) transcription factors (He et al., 2018; Figure 4). Overexpression of miR156 and subsequent downregulation of SPL3/5 resulted in delayed flowering period of A. thaliana; downregulation of SPL9 and SPL15 resulted in shortened leaf plastochrons, slower growth, and extremely abundant leaves of A. thaliana (Schwab et al., 2005; Wu and Poethig, 2006; Xu et al., 2016b; Zhang et al., 2019). The role of miR156 and SPLs in flower development was also reported in rice (Xie et al., 2006). Studies have shown that the fine negative regulation of miR156 on SPL3 ultimately affects the flowering phase transition process of $A$. thaliana by changing the expression of the FT gene in A. thaliana leaves leading to delayed flowering (Kim et al., 2012). Similar to the function of juvenile hormones in insects, high concentrations of miR156 keeps plants in the juvenile developmental stage. As development progresses, the amount of miR156 decreases gradually, which promotes the 


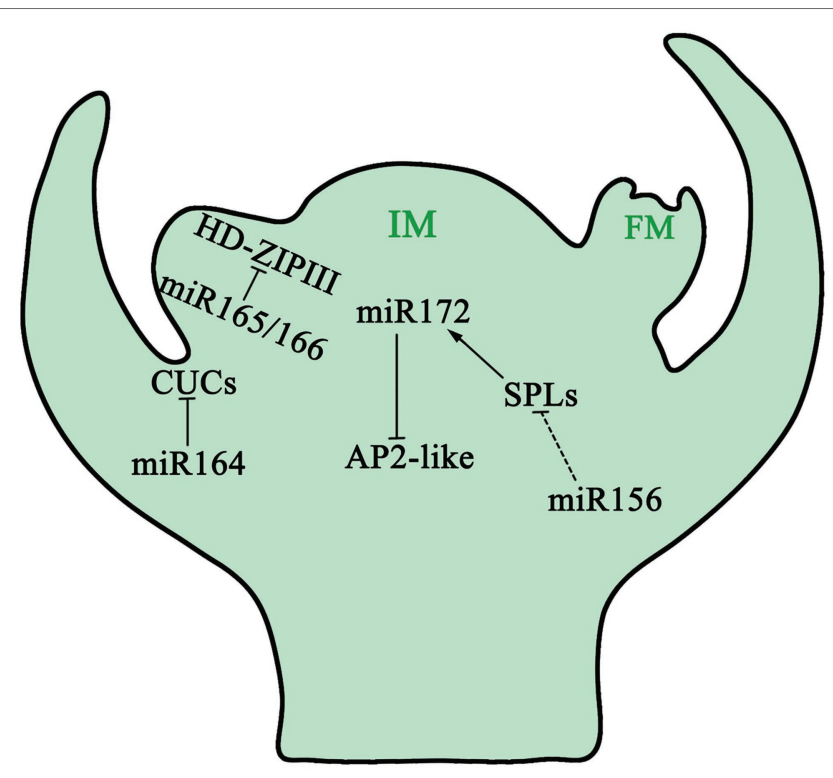

FIGURE 4 | The function of miRNAs in inflorescence meristem. As plants change growing phases from juveniles to adults, downregulation of miR156 dampens the inhibition of SPL expression, which in turn promotes miR172 transcription. miR172 triggers the development of inflorescence meristem by reducing the mRNA level of $A P 2$-like genes. Spatiotemporal functions of miR165/166 and their targets HD-ZIP III genes, together with miR164, restrict the functions of CUCs in specific regions of the boundary to maintain the inflorescence meristem. miR156 decreases during IM development, whereas miR172 increases. IM: Inflorescence Meristem; FM: Floral Meristem.

juvenile-to-adult transition. Further studies showed that the decrease of miR156 content was not related to the absolute age (i.e., absolute time) of plants, but associated with the physiological age of plants (Cheng et al., 2021b).

miR172 is similar to miR156: namely, both are involved in controlling flowering time and the formation of floral organs by degrading and inhibiting target mRNA (Jung et al., 2007). miR172 regulates the transformation of plant development from the juvenile to flowering stage by regulating AP2-like genes including SM-LIKE 2, SCHNARCHZAPFEN, and TARGET OF EARLY ACTIVATION TAGGED 1/2/3. miR172 regulates plant flowering time, flower organ determination, flower morphogenesis, and plant development by controlling AP2 transcription factors (Aukerman and Sakai, 2003). Overexpression of miR172 in $A$. thaliana will promote early flowering, while overexpression of AP2 genes will delay flowering.

In addition, miR156 and miR172 interact together in some parts of the plant growth cycle that are regulated by miRNA. miR156 inhibited the expression of the SPL family, while some SPLs promoted the expression of miR172. Previous studies have shown that the miR156-SPL-miR172 pathway in A. thaliana is the decisive factor in controlling the juvenile-to-adult transition. The miR156-SPL-miR172 pathway can be divided into two modules: the leaf module and the apical meristem module, both of which have different combinations of SPL and miR172 encoding gene modules. In leaves, the SPL9-miR172b/c modules regulate flowering time by regulating the expression of the FT gene; while in apical meristem, the SPL15-miR172d modulus promotes flowering by activating the expression of MADS-box genes. In addition, the expression of the MIR172 gene can be regulated by ambient temperature and photoperiod, and different MIR172 genes have different response patterns (Lian et al., 2021).

Other miRNAs, such as miR159 and miR319, also function in flowering development. Their target genes are $M Y B$ and TCP (TCP FAMILY TRANSCRIPTION FACTOR) transcription factors, respectively. Overexpression of miR159 and miR319 will cause floral development disorders, such as delayed flowering (Palatnik et al., 2007). miR159 can regulate the expression of MYB33 and MYB65, and a loss-of-function miR159 displays strong pleiotropic defects, stunted growth, curled leaves, defective sepals, petals, and anthers in A. thaliana (Achard et al., 2004; Millar and Gubler, 2005; Tsuji et al., 2006; Yu et al., 2012). At the same time, miR159 can prevent the over-activation of miR156, thus regulating the phase transition of $A$. thaliana in vegetative developmental period (Guo et al., 2017). MYB33, the target of miR159, promotes the transcription of $A B A$ INSENSITIVE 5 (ABI5) by binding directly to its promoter, then $A B I 5$ plays a role in the upstream of miR156 and regulates the juvenile-to-adult transition in Arabidopsis by affecting the gene expression in the miR156-SPL pathway (Guo et al., 2021).

In A. thaliana, miR164 regulates the number of petals and the differentiation of floral organ marginal cells and apical meristem cells by increasing the accumulation of CUC transcription factors in the boundary. Meanwhile, overexpression of miR164 leads to sepal fusion and reduction of petal number, suggesting that miR164 is related to the activity of flower meristem and the specific boundary division of the meristem region (Laufs et al., 2004; Jung et al., 2009).

miR165/166 also regulates flower morphogenesis. miR166/165 gene showed tissue-specific expression patterns in different flower organs. miR166a was mainly expressed in stamens, while miR166b was highly expressed in ovule and stigma. miR166d and miR165a were highly expressed in ovule. In contrast, miR166g had a broad expression in the stigma, stamen, and receptacle, but not in the ovule (Jung and Park, 2007). In terms of meristem activity regulation, miR165/166 is closely related to meristem formation in floral organs (Zhang et al., 2007). In the Arabidopsis mutants with miR165/166 overexpression, the flower structure was seriously damaged. For example, when miR166 is overproduced in mum enhancer 1 and jabba mutants, and the pistil population is very small and the number of carpels is also reduced.

The significant increase of miR396 expression can cause the bending of the stigma in flowers, which demonstrated that miR396 also participates in the regulation of flower development. In A. thaliana, excessive production of miR167 displays floral defects resulting to that filaments were abnormally short, anthers could not properly release pollen, and pollen grains did not germinate ( $\mathrm{Ru}$ et al., 2006). ARF6 and ARF8, the target genes of miR167, play a meaningful role in the regulation of pistil and stamen population. miR167 also controls the fertility of male and female flowers of A. thaliana (Wu et al., 2006). 
In addition to regulating reproductive organ morphology in the model organism $A$. thaliana, miRNAs have also been shown to regulate these organs in other plants. Tomato miR156b performs a key role in controlling flower and fruit morphology by regulating meristem activity and the initial stage of fruit development. Also, in tomato, overexpression of $A$, thaliana miR167a causes the downregulation of ARF6 and ARF8, resulting in serious disorders in floral organ development and female gamete fertility (Liu et al., 2014b). In Petunia and Antirrhinum species, researchers found that miR169 can partially replace AP2, which results from the fact miR169 can regulate transcription factor NF-YA, thus affecting the development of flower organs (Chen, 2004; Cartolano et al., 2007; Zhao et al., 2009; Waheed and Zeng, 2020).

miRNAs also regulate flower and seed production in monocots. In rice, Zhu et al. found that overexpression of miR172 can cause spikelet deletion, floral organ development malformation, and fertility reduction (Zhu et al., 2009). OsmiR397 is a miRNA that is expressed at a high level in the young panicles and grains of rice, which increases grain yield by downregulating its target gene OsLAC. Overexpression of OsmiR397 can increase grain size and promote panicle branching (Zhang et al., 2013). In maize, Chuck et al. showed that miRNA-targeting SBP-box transcription factor tasselsheath4 plays a critical role in the development of maize bracts and the establishment of meristem boundaries in inflorescences (Chuck et al., 2010, 2014) auxin.

\section{Other Processes Involving miRNAs}

miRNA also plays an essential regulatory role in other developmental processes. In A. thaliana, auxin response factors ARF10, ARF16, and ARF17 are targeted by miR160. Studies have shown that miR160 plays a very important role in the negative regulation of ARF10 to promote seed germination (Liu et al., 2007). Llave et al. found that during Arabidopsis root growth, root cap cell formation is related to miR160, which controls stem cell differentiation at the end of the root meristematic region and determines root growth direction by regulating the expression of ARF10 (Figure 3; Llave et al., 2002).

In addition, miR164 and miR390 greatly influence the development of plant root organs, including root cap formation, lateral root development, and adventitious root formation (Yoon et al., 2010). The process of lateral root growth of $A$. thaliana is regulated by miR164. Guo et al. found that miR164 can mediate NAC1 expression after being induced by auxin, thus affecting auxin transmission and regulating lateral root growth (Figure 3; Guo et al., 2005).

miR165/166 is related to the formation of xylem and cell arrangement in plants. The regulation of miRNA on plant tissue development is a complex molecular process (Figure 3; Carlsbecker et al., 2010). The same miRNA may have the multiple functions in different tissues. For example, miR165/ miR166 is also related to leaf polarization in addition to xylem and cell arrangement as mentioned in a previous section (Tatematsu et al., 2015; Manuela and Xu, 2020).

Furthermore, miRNA is involved in regulating plant morphological structure and yield, which is important in crop plants. In soybean, the miR156-SPL gene module plays a key role in regulating the morphological structure and yield of soybean. In transgenic soybean overexpressing miR156b, axillary bud formation and branching are regulated by reducing the expression amount of SPL9d (Wang and Wang, 2015). In rice, inhibiting the expression of miR1432 or overexpressing OsACOT (Acyl-CoA Thioesterase) can cause the grain weight to be significantly boosted by increasing the grain filling rate, which can improve crop yield (Zhao et al., 2019). Genetic analysis shows that OsSPL7 is the target of miR156f, which regulates plant morphological structure, namely tillering and height of rice (Dai et al., 2018). At the same time, OsSPL7 directly binds to the OsGH3.8 promoter to regulate its transcription, indicating that the miR156fOsSPL7-OsGH3.8 is the complete regulatory pathway for these traits in rice.

miRNA is widely connected to plant diseases and environmental stress responses. Virus infections can greatly influence plant morphology and productivity. More and more evidence has shown that miRNA is related to virus-mediated diseases and virus-induced gene silencing (Chapman et al., 2004). More than 30 RNA silencing suppressors, also known as pathogenic factors, have been identified from plant viruses, including p19, p21, p25, and p69. Pathogenic factors can usually hinder the formation of siRNA, affect the stability of siRNA, or interfere with the combination of siRNA and RISC complexes, and can also lead to the generation of other diseases in plants and cause developmental malformation. Excessive HC-Pro protease (helper-component proteinase) in plants will reduce miR171 level and produce developmental deletion plants associated with miR171 which included branching defects, an increased number of short vegetative phytomers and late flowering. Through the overexpression of the Hc-Pro gene in A. thaliana, it was found that most miR171 target mRNAs are increased which results in virus-mediated diseases in plants (Kasschau et al., 2003).

Under abiotic stress, plants can directly synthesize some miRNAs and induce low or excessive expression of other miRNAs. These miRNAs act on transcription factors related to stress resistance, Plant Growth Regulator 9 response protein genes, stress tolerance protein genes, and other target genes, which enables plants to quickly respond to environmental changes. In plants, miRNA responding to stress was first found in A. thaliana (Jones-Rhoades and Bartel, 2004). The expression of miR393 in A. thaliana was significantly upregulated after low temperature, drought, salt, or hormone (ABA) treatment. However, no responses to drought or $\mathrm{NaCl}$ were observed when miR310 and miR319 were upregulated after low-temperature stress indicating that these two miRNAs only function in low-temperature response. miR389a was downregulated after the above stress was induced (Sunkar and Zhu, 2004). miR393, miR397, miR402 (Sunkar and Zhu, 2004), miR165/miR166, miR169, and miR172 (Zhou et al., 2008) were all found to be induced by low temperature to enhance the plant resistance. In $A$. thaliana, the expression level of miR395 increased in the absence of sulfate, while the expression level of miR399 was upregulated, and the mRNA level of its target gene PHO2/UBC24 (PHOSPHATE 2) was lower 
(Chiou et al., 2006). miR169 is downregulated in a drought environment. Compared to wild-type plants, plants overexpressing miR169a or plants with Nuclear transcription factor $Y$ subunit A-5 deletion of miR169's target gene are more likely to lose leaf water and are more sensitive to drought (Li et al., 2008). In grapevine, miR398 participates in plant biotic stress, heavy metals, high salt, drought, ultraviolet radiation, and other abiotic stresses through the targeted regulation of two superoxide dismutases, COPPER/ZINC SUPEROXIDE DISMUTASE $1 / 2$ (Leng et al., 2017).

As mentioned above, studies in Arabidopsis thaliana and other plants have showed that miRNAs participate in many biological processes. Compared with the plant-wide action of hormones, miRNAs are crucial in precise regulation of gene expression in a tissue-specific pattern. How the plants integrate miRNAs fine regulation into hormonal system pathway to modulate tissue formation deserves more attention. Study the role and mechanism of miRNA movement between cells and tissues are vital to understand miRNA function.

\section{THE INTERACTION BETWEEN MIRNAS AND PLANT HORMONES}

Plant hormones are important regulatory factors synthesized in plants. They regulate plant growth, development, and differentiation either individually or together. Plant hormones mainly include auxin (AUX), cytokinin (CK), abscisic acid (ABA), gibberellic acid (GA), ethylene (ET), brassinosteroid (BR), and jasmonic acid (JA). As signaling molecules regulating plant growth and development, these hormones have absolutely necessary function in controlling development timing, metabolism, and stress response through the whole plant growth cycle. Specific stages of development often involve the participation of multiple hormones; this enables plant cells to respond adaptively to development signals and changes in their internal and external environment (Li et al., 2020). miRNAs coordinate with hormones by negatively regulating target genes in hormonal pathways. It was found that in the seedlings, the overall miRNA accumulation level decreased after HYL1 mutation, which displayed a variety of developmental defect phenotypes and abnormal sensitivity to $\mathrm{ABA}, \mathrm{AUX}$, and $\mathrm{CK}$, indicating that miRNA is related to the signal responses of these hormones (Han et al., 2004). Many miRNA gene promoters contain hormone response elements as well as cis-elements response to stresses, indicating that the regulation of miRNA gene transcription may be a way of hormone and stress response (Ding et al., 2013).

miRNAs regulate auxin receptors and several transcription factors in plants. In Arabidopsis, when the expression of miR160 was silenced, the expression levels of ARF16 and ARF17 genes increased, which led to abnormal germ development, cotyledon shape defect, slow inflorescence development, stamen reduction, root shortening, and other adverse developmental symptoms. However, overexpression of miR160 in Arabidopsis inhibited the development of root cap and increased the number of lateral roots (Figure 3; Mallory et al., 2005; Wang et al., 2005). These results indicate that precise accumulation of miR160 is crucial to auxin-related plant development. miR167 and ARF6/8 co-regulate adventitious root formation (Gutierrez et al., 2009). miR847 targets and silences IAA28, the AUX/IAA inhibitory protein, to activate the auxin signaling pathway. The ubiquitination-mediated degradation of the IAA28 protein combined with miR847/IAA28 mRNA regulatory module to achieve the rapid disinhibition of the auxin signaling pathway (Wang and Guo, 2015). At the same time, miR165/166 directly targets $P H B$, an activator of ARF5, and then triggers the expression of miR390, which directly lead to the accumulation of ta-siRNAs (tasiR-ARF3/4; Marin et al., 2010; Muller et al., 2016; Dastidar et al., 2019). In addition, the miR165/166-tasiRARFs module also establishes the paraxial/distal polarity of the blade.

miR159 and miR319 inhibit the expression of SHOOTMERISTEMLESS and BREVIPEDICELLUS, and then enhance the expression of IPT (ISOPENTENYL TRANSFERASE) and promote the biosynthesis of CK in SAM (Rubio-Somoza and Weigel, 2013; Scofield et al., 2014). At the cytokinin signal transduction level, the miR156-SPL9 complex modulates cytokinin-related plant regeneration by inhibiting the B-type ARR genes9 [type B Arabidopsis Response Regulators (ARRs)], which are transcription factors that act as positive regulators in the two-component cytokinin signaling pathway (Zhang et al., 2015).

miRNAs also affect the biosynthesis and signal transduction of cytokinin through auxin, and then continue to maintain the dynamic balance between auxin and cytokinin, such as miR160 and miR165/6 (Dello et al., 2012; Liu et al., 2016). Another signaling molecule, gibberellin, can regulate the levels of various miRNAs through DELLA (aspartic acid-glutamic acid-leucine-leucine-alanine) protein and its interacting proteins, such as IDD2 (indeterminate (ID)-domain 2), PHYTOCHROMEINTERACTING FACTOR 4, or SCARECROW-LIKE (SCL; Han et al., 2014; Fan et al., 2018). Conversely, miRNAs can directly regulate GA biosynthesis and signal transduction through different complexes such as miR156-SPL, miR171-SCL, and miR159-GAMYB(L)s modules (Yu et al., 2012; Ma et al., 2014; Sun et al., 2018; Millar et al., 2019). Brassinosteroids (BR) negatively regulate miRNA-mediated translation inhibition of target genes by interfering with the distribution and localization pattern of AGO1, the miRNA effector protein, in the endoplasmic reticulum (Wang et al., 2021d).

miRNAs can regulate seed germination and leaf senescence by affecting the levels of ABA and ethylene. ABA, the signaling hormone, and SnRK2 (SNF1-related protein kinase 2) protein kinase, the core component of the osmotic stress response pathway, can regulate miRNA synthesis (Yan et al., 2017). At the same time, the ABA and ethylene signaling pathway can cause feedback on the level of sRNA by affecting the core protein in sRNA synthesis pathway, such as CBP20 (CAP-BINDING PROTEIN 20; Kim et al., 2008; Li et al., 2012, 2013; Zhang et al., 2016). Therefore, miRNAs coordinate with hormone responses in many ways and play an important role in plant development. 


\section{ROLE OF SMALL RNA MOVEMENT IN PLANT DEVELOPMENT}

Plant small RNAs can spread silencing signals by moving in plants to participate in plant development regulation and respond to environmental stresses. Usually, mobile small RNAs generate sharply defined domains of target gene expression through an intrinsic and direct threshold-based readouts of their mobility gradients to drive developmental patterning (Skopelitis et al., 2017). There are two main types of small RNA movement in plants: one is short-distance (cell-to-cell) movement between neighboring cells, the other is long-distance (such as shoot to root or root to shoot) movement in plants. Currently, there is a hypothesis that 21 nt-siRNA are mainly involved in short-distance transport and 23lu201324 nt small RNAs are mainly involved in longdistance transport. The mechanisms of these two types of small RNA movement may be different (Tamiru et al., 2018), and will be explored in the following sections.

\section{Short-Distance Movement}

The short-distance movement of plant small RNAs is was thought to be mainly conferred via plasmodesmata between adjacent cells (Vaten et al., 2011). However, using a type of miR-GFP sensor system, it has been found that small RNAs are an independent mobile unit, and their mechanisms of movement between cells are different from that of proteins (Skopelitis et al., 2018). Some small RNAs have been discovered that can move in short distances of up to ten files of cells. For example, mature miR165/166 can move from the endoderm of the root to the vasculature, thereby forming a gradientlike distribution of miR165/166 to regulate the expression pattern of its target gene $P H B$ and finally complete the establishment of proto- and metaxylem (Carlsbecker et al., 2010). In leaves, miR165/166 can be moved from the abaxial surface to the adaxial side, also forming a gradient to regulate the expression pattern of HD-ZIP III genes and ultimately form leaf polarity. In the SAM, miR394 moves to the cells in the L2 and L3 layers to repress its target gene LCR as a mobile signal produced by L1 layer cell. Repression of LCR signal in the underneath stem cells is used to maintain stem cell pluripotency by influencing the WUS-CLV loop (Knauer et al., 2013). In addition to miRNAs, PhasiRNAs have also been found to be able to move from cell to cell. For example, tasiR-ARF is produced from long non-coding RNAs transcribed at the TAS3 loci by the processing of the miR390-AGO7 complex on the adaxial side of leaves (Allen et al., 2005; Endo et al., 2013). These tasiR-ARFs can move to the abaxial side of leaves and form a gradient of to inhibit the expression of $A R F 3$ on adaxial side. Inhibition of ARF3 expression ensures the establishment of leaf polarity patterns (Chitwood et al., 2009). Recent experiments show that processed tasiR-ARFs in the apical epidermal cells can move to hypodermal cells in the nucellar region to repress ARF3 expression and suppress ectopic megaspore mother cell (MMC) fate (Su et al., 2020).

\section{Long-Distance Movement}

The long-distance movement of plant small RNA is mainly mediated through the phloem following source-sink relationships (Melnyk et al., 2011; Tamiru et al., 2018). In line with this, miRNAs have been found in the phloem saps of multiple plants (Tamiru et al., 2018). For example, miR172 was found in the vascular bundles of potatoes, indicating that miR172 might be mobile or that it regulates long-distance signals to induce tuberization(Marin et al., 2010). In Brassica napus, using small RNA sequencing, it was discovered that levels of miR395, miR398, and miR399 in the phloem are strongly increased in response to sulphate, copper, or phosphate starvation, respectively (Buhtz et al., 2008).

In Arabidopsis, miR399 moves from shoot to root to inhibit the expression of its target gene $\mathrm{PHO} 2$ in response to phosphate homeostasis (Lin et al., 2008; Pant et al., 2008). During phosphate starvation, miR827 and miR2112a can also move from shoot to root (Huen et al., 2017). miR2112 can move from shoot to root to inhibit the expression of symbiosis suppressor TOO MUCH LOVE, thereby controlling rhizobial infection (Tsikou et al., 2018).

\section{FUTURE PERSPECTIVES}

Understanding the elaborate regulation of plant development by miRNAs is crucial for crop breeding. Knocking out dominant genes in development often causes lethality in plants, while miRNAs can safely modify gene expression to some extent and improve plant development. In rice, the number of branches (including tiller and inflorescence branches) determines grain yield. It was found that the genes regulating rice tillering and panicle branching consisted of miR156/miR529/SPL and miR172/ AP2 modules. The SPL gene negatively controls tillering, but positively regulates the transformation of inflorescence meristem and spikelet. Changes in SPL expression will reduce panicle branching (Wang and Wang, 2015). In the regulation of seed size and grain yield, OsmiR397 can increase grain size, promote panicle branching, and increase grain yield by downregulating its target gene OsLAC (Zhang et al., 2013). miR1432-OsACOT modules are involved in fatty acid metabolism and plant hormone biosynthesis, and crucial for rice (Zhao et al., 2019). miR319s negatively affects tiller number and grain yield by targeting OsTCP21 and OsGAmyb (Wang et al., 2021c). Changes of "miR168-AGO1" regulatory pathway influence several "miRNAtarget gene" loops, which regulate the immunity and growth of rice, respectively. Among these, the "miR535-SPL14" loop regulates the yield and immunity of rice, the "miR164-NAC11" loop regulates the growth period and immunity of rice, and miR1320 regulates the immunity of rice (Wang et al., 2021a). In maize, TASSELSEED4 encodes miR172 to control sex determination and meristem cell fate by targeting IDS1 (Indeterminate Spikelet1). Moreover, miR156a-l acts on several SPL genes during the transition from young to mature ear, and indirectly activates miR172 through SPLs (Lauter et al., 2005; Chuck et al., 2007b; Salvi et al., 2007). In agriculture, epigenetic variations account for a great proportion for change 
in crop yield. SNPs located in non-coding regions are paid more and more attention by breeders in population genetic analysis and traditional hybrid breeding. New strategies such as Short Tandem Target Mimic (STTM), a specific miRNA targeting method which is effective in blocking small RNA functions in plants (Tang et al., 2012), are adapted and utilized in generating transgenic crops. As MIR genes are usually short, EMS mutation and T-DNA inserted mutation are difficult to achieve ideal mutants for $M I R$ genes. However, the advances of genome editing technologies make modification of miRNA expression to increase crop yield become easier.

Modes of miRNA function need to be further explored. miRNAs also act as environmental response factors, endowing plants with corresponding phenotypes and promoting plant evolution and adaptation. For example, the essential role of HD-ZIP III-miR165/166 signaling pathway in meristematic tissues and the dual regulatory role of miR156/miR172 in flower determination are conserved in plant kingdom. The function of miRNAs and their specific mechanisms need to be further studied. It is still not clearly understood how miRNAs specifically regulate a biological process in certain temporal and spatial patterns. Many miRNA gene promoters contain plant hormones and cis-elements of stress response, indicating that regulation of miRNA gene transcription may be a way to respond to plant hormone and stresses. The expression of $A G O 10$ is precisely regulated by auxin, brassinolide, and light to initiate axillary meristem in certain leaf axils. This provides a way to modify gene expression in a tissue-specific pattern and potentiate modulation of organ development at certain stages.

Recently, great importance has been attached to small RNA movement between cells, tissues as well as organisms by plant researchers. Much effort is made to uncover the role and mechanism of small RNA movement. So far, it is evidenced that miRNA can move to form gradient distribution between different tissues. After biogenesis, miRNA is protected from degradation and is transported to destination cells. It is noteworthy that miRNA

\section{REFERENCES}

Abdel-Ghany, S. E., and Pilon, M. (2008). MicroRNA-mediated systemic downregulation of copper protein expression in response to low copper availability in Arabidopsis. J. Biol. Chem. 283, 15932-15945. doi: 10.1074/jbc.M801406200

Achard, P., Herr, A., Baulcombe, D. C., and Harberd, N. P. (2004). Modulation of floral development by a gibberellin-regulated microRNA. Development 131, 3357-3365. doi: 10.1242/dev.01206

Allen, R. S., Li, J., Stahle, M. I., Dubroue, A., and Gubler, F. (2007). Genetic analysis reveals functional redundancy and the major target genes of the Arabidopsis miR159 family. Proc. Natl. Acad. Sci. U. S. A. 104, 16371-16376. doi: 10.1073/pnas.0707653104

Allen, E., Xie, Z., Gustafson, A. M., and Carrington, J. C. (2005). MicroRNAdirected phasing during trans-acting siRNA biogenesis in plants. Cell 121, 207-221. doi: 10.1016/j.cell.2005.04.004

Arikit, S., Xia, R., Kakrana, A., Huang, K., and Zhai, J. (2014). An atlas of soybean small RNAs identifies phased siRNAs from hundreds of coding genes. Plant Cell 26, 4584-4601. doi: 10.1105/tpc.114.131847

Aukerman, M. J., and Sakai, H. (2003). Regulation of flowering time and floral organ identity by a MicroRNA and its APETALA2-like target genes. Plant Cell 15, 2730-2741. doi: 10.1105/tpc.016238 needs to reach a certain threshold level before it can function in a non-cellular autonomous way. How intermediate steps influence miRNA movement and its non-cellular autonomous function need more studies. To understand and prime plants for abiotic stresses, it is also worth further studies to elaborate the correlation between hormone concentration and miRNA movement.

In addition, biotic and abiotic stresses can induce plants to produce new sRNA. For example, $A$. thaliana can produce a large number of $22 \mathrm{nt}$ siRNAs dependent on DCL2 and RDR6 under stresses such as nitrogen deficiency. However, it is still a puzzle as to why only a small number of gene loci in $A$. thaliana can produce $22 \mathrm{nt}$ siRNAs. Meanwhile, there is also a big gap in knowledge of the synthesis of $22 \mathrm{nt}$ siRNAs to their biological function. More evidence is needed to verify whether $22 \mathrm{nt}$ siRNAs can also regulate target genes in distal organs due to the cellular non-autonomy of sRNA. Therefore, the improvement of sequencing technology and miRNA research methods are highly recommended here. With the help of various single-cell omics and nanopore sequencing, more miRNAs, their action mechanisms, and their regulatory pathways will be discovered in model plants, which will provide important theoretical basis for understanding how miRNA regulates plant growth and development and can then be applied to agriculturally important plants.

\section{AUTHOR CONTRIBUTIONS}

$\mathrm{QD}, \mathrm{BH}$, and $\mathrm{CZ}$ wrote the article. All authors read and approved the manuscript.

\section{FUNDING}

Research in the Zhang lab is supported by the Strategic Priority Research Program of the Chinese Academy of Sciences, Grant Nos. XDA26030200 and XDA24010106-2 to CZ.

Baucher, M., Moussawi, J., Vandeputte, O. M., Monteyne, D., and Mol, A (2013). A role for the miR396/GRF network in specification of organ type during flower development, as supported by ectopic expression of Populus trichocarpa miR396c in transgenic tobacco. Plant Biol. 15, 892-898. doi: $10.1111 /$ j.1438-8677.2012.00696.x

Baumann, K. (2013). Plant cell biology: Mobile miRNAs for stem cell maintenance. Nat. Rev. Mol. Cell Biol. 14:128. doi: 10.1038/nrm3529

Baumberger, N., and Baulcombe, D. C. (2005). Arabidopsis ARGONAUTE1 is an RNA slicer that selectively recruits microRNAs and short interfering RNAs. Proc. Natl. Acad. Sci. U. S. A. 102, 11928-11933. doi: 10.1073/pnas.0505461102

Bazin, J., Khan, G. A., Combier, J. P., Bustos-Sanmamed, P., and Debernardi, J. M. (2013). MiR396 affects mycorrhization and root meristem activity in the legume Medicago truncatula. Plant J. 74, 920-934. doi: 10.1111/tpj.12178

Bergmann, D. C., and Sack, F. D. (2007). Stomatal development. Annu. Rev. Plant Biol. 58, 163-181. doi: 10.1146/annurev.arplant.58.032806.104023

Blein, T., Pulido, A., Vialette-Guiraud, A., Nikovics, K., and Morin, H. (2008). A conserved molecular framework for compound leaf development. Science 322, 1835-1839. doi: 10.1126/science.1166168

Bologna, N. G., Iselin, R., Abriata, L. A., Sarazin, A., and Pumplin, N. (2018). Nucleo-cytosolic shuttling of ARGONAUTE1 prompts a revised model of the plant MicroRNA pathway. Mol. Cell 69, 709-719. doi: 10.1016/j. molcel.2018.01.007 
Borges, F., and Martienssen, R. A. (2015). The expanding world of small RNAs in plants. Nat. Rev. Mol. Cell Biol. 16, 727-741. doi: 10.1038/nrm4085

Bresso, E. G., Chorostecki, U., Rodriguez, R. E., Palatnik, J. F., and Schommer, C. (2018). Spatial control of gene expression by miR319-regulated TCP transcription factors in leaf development. Plant Physiol. 176, 1694-1708. doi: $10.1104 /$ pp.17.00823

Brioudes, F., Jay, F., Sarazin, A., Grentzinger, T., and Devers, E. A. (2021). HASTY, the Arabidopsis EXPORTIN5 ortholog, regulates cell-to-cell and vascular microRNA movement. EMBO J. 40:e107455. doi: 10.15252/ embj.2020107455

Brodersen, P., Sakvarelidze-Achard, L., Bruun-Rasmussen, M., Dunoyer, P., and Yamamoto, Y. Y. (2008). Widespread translational inhibition by plant miRNAs and siRNAs. Science 320, 1185-1190. doi: 10.1126/science.1159151

Buhtz, A., Springer, F., Chappell, L., Baulcombe, D. C., and Kehr, J. (2008). Identification and characterization of small RNAs from the phloem of Brassica napus. Plant J. 53, 739-749. doi: 10.1111/j.1365-313X.2007.03368.x

Bustos-Sanmamed, P., Mao, G., Deng, Y., Elouet, M., and Khan, G. A. (2013). Overexpression of miR160 affects root growth and nitrogen-fixing nodule number in Medicago truncatula. Funct. Plant Biol. 40, 1208-1220. doi: 10.1071/FP13123

Cambiagno, D. A., Giudicatti, A. J., Arce, A. L., Gagliardi, D., and Li, L. (2021). HASTY modulates miRNA biogenesis by linking pri-miRNA transcription and processing. Mol. Plant 14, 426-439. doi: 10.1016/j. molp.2020.12.019

Carbonell, A., Fahlgren, N., Garcia-Ruiz, H., Gilbert, K. B., and Montgomery, T. A. (2012). Functional analysis of three Arabidopsis ARGONAUTES using slicer-defective mutants. Plant Cell 24, 3613-3629. doi: $10.1105 /$ tpc.112.099945

Carlsbecker, A., Lee, J. Y., Roberts, C. J., Dettmer, J., and Lehesranta, S. (2010). Cell signalling by microRNA165/6 directs gene dose-dependent root cell fate. Nature 465, 316-321. doi: 10.1038/nature08977

Cartolano, M., Castillo, R., Efremova, N., Kuckenberg, M., and Zethof, J. (2007). A conserved microRNA module exerts homeotic control over Petunia hybrida and Antirrhinum majus floral organ identity. Nat. Genet. 39, 901-905. doi: 10.1038/ng2056

Caruana, J. C., Dhar, N., and Raina, R. (2020). Overexpression of Arabidopsis microRNA167 induces salicylic acid-dependent defense against pseudomonas syringae through the regulation of its targets ARF6 and ARF8. Plant Direct 4:e270. doi: 10.1002/pld3.270

Chandran, V., Wang, H., Gao, F., Cao, X. L., and Chen, Y. P. (2018). MiR396OsGRFs module balances growth and rice blast disease-resistance. Front. Plant Sci. 9:1999. doi: 10.3389/fpls.2018.01999

Chapman, E. J., Prokhnevsky, A. I., Gopinath, K., Dolja, V. V., and Carrington, J. C. (2004). Viral RNA silencing suppressors inhibit the microRNA pathway at an intermediate step. Genes Dev. 18, 1179-1186. doi: 10.1101/gad.1201204

Chen, X. (2004). A microRNA as a translational repressor of APETALA2 in Arabidopsis flower development. Science 303, 2022-2025. doi: 10.1126/ science. 1088060

Chen, Z. H., Bao, M. L., Sun, Y. Z., Yang, Y. J., and Xu, X. H. (2011). Regulation of auxin response by miR393-targeted transport inhibitor response protein 1 is involved in normal development in Arabidopsis. Plant Mol. Biol. 77, 619-629. doi: 10.1007/s11103-011-9838-1

Chen, H. M., Chen, L. T., Patel, K., Li, Y. H., and Baulcombe, D. C. (2010). 22-nucleotide RNAs trigger secondary siRNA biogenesis in plants. Proc. Natl. Acad. Sci. U. S. A. 107, 15269-15274. doi: 10.1073/pnas.1001738107

Chen, X., and Rechavi, O. (2021). Plant and animal small RNA communications between cells and organisms. Nat. Rev. Mol. Cell Biol. doi: 10.1038/ s41580-021-00425-y [Epub ahead of print].

Cheng, X., He, Q., Tang, S., Wang, H., and Zhang, X. (2021a). The miR172/ IDS1 signaling module confers salt tolerance through maintaining ROS homeostasis in cereal crops. New Phytol. 230, 1017-1033. doi: 10.1111/ nph.17211

Cheng, Y. J., Shang, G. D., Xu, Z. G., Yu, S., and Wu, L. Y. (2021b). Cell division in the shoot apical meristem is a trigger for miR156 decline and vegetative phase transition in Arabidopsis. Proc. Natl. Acad. Sci. U. S. A. 118:e2115667118. doi: 10.1073/pnas.2115667118

Chiou, T. J., Aung, K., Lin, S. I., Wu, C. C., and Chiang, S. F. (2006). Regulation of phosphate homeostasis by MicroRNA in Arabidopsis. Plant Cell 18, 412-421. doi: 10.1105/tpc.105.038943
Chitwood, D. H., Nogueira, F. T., Howell, M. D., and Montgomery, T. A. (2009). Pattern formation via small RNA mobility. Genes Dev. 23, 549-554. doi: $10.1101 /$ gad.1770009

Chuck, G. S., Brown, P. J., Meeley, R., and Hake, S. (2014). Maize SBP-box transcription factors unbranched 2 and unbranched 3 affect yield traits by regulating the rate of lateral primordia initiation. Proc. Natl. Acad. Sci. U. S. A. 111, 18775-18780. doi: 10.1073/pnas.1407401112

Chuck, G., Cigan, A. M., Saeteurn, K., and Hake, S. (2007a). The heterochronic maize mutant Corngrass1 results from overexpression of a tandem microRNA. Nat. Genet. 39, 544-549. doi: 10.1038/ng2001

Chuck, G., Meeley, R., Irish, E., Sakai, H., and Hake, S. (2007b). The maize tasselseed 4 microRNA controls sex determination and meristem cell fate by targeting Tasselseed6/indeterminate spikelet1. Nat. Genet. 39, 1517-1521. doi: $10.1038 /$ ng.2007.20

Chuck, G., Whipple, C., Jackson, D., and Hake, S. (2010). The maize SBP-box transcription factor encoded by tasselsheath4 regulates bract development and the establishment of meristem boundaries. Development 137, 1243-1250. doi: $10.1242 /$ dev. 048348

Curaba, J., Talbot, M., Li, Z., and Helliwell, C. (2013). Over-expression of microRNA171 affects phase transitions and floral meristem determinancy in barley. BMC Plant Biol. 13:6. doi: 10.1186/1471-2229-13-6

D’Ario, M., Griffiths-Jones, S., and Kim, M. (2017). Small RNAs: big impact on plant development. Trends Plant Sci. 22, 1056-1068. doi: 10.1016/j. tplants.2017.09.009

Dai, X., Lu, Q., Wang, J., Wang, L., and Xiang, F. (2021). MiR160 and its target genes ARF10, ARF16 and ARF17 modulate hypocotyl elongation in a light, BRZ, or PAC-dependent manner in Arabidopsis: MiR160 promotes hypocotyl elongation. Plant Sci. 303:110686. doi: 10.1016/j. plantsci.2020.110686

Dai, Z., Wang, J., Yang, X., Lu, H., and Miao, X. (2018). Modulation of plant architecture by the miR156f-OsSPL7-OsGH3.8 pathway in rice. J. Exp. Bot. 69, 5117-5130. doi: 10.1093/jxb/ery273

Dastidar, M. G., Scarpa, A., Magele, I., Ruiz-Duarte, P., and von Born, P. (2019). ARF5/MONOPTEROS directly regulates miR390 expression in the Arabidopsis thaliana primary root meristem. Plant Direct 3:e116. doi: 10.1002/ pld3.116

Debernardi, J. M., Mecchia, M. A., Vercruyssen, L., Smaczniak, C., and Kaufmann, K. (2014). Post-transcriptional control of GRF transcription factors by microRNA miR396 and GIF co-activator affects leaf size and longevity. Plant J. 79, 413-426. doi: 10.1111/tpj.12567

Debernardi, J. M., Rodriguez, R. E., Mecchia, M. A., and Palatnik, J. F. (2012). Functional specialization of the plant miR396 regulatory network through distinct microRNA-target interactions. PLoS Genet. 8:e1002419. doi: 10.1371/ journal.pgen.1002419

Dello, I. R., Galinha, C., Fletcher, A. G., Grigg, S. P., and Molnar, A. (2012). A PHABULOSA/cytokinin feedback loop controls root growth in Arabidopsis. Curr. Biol. 22, 1699-1704. doi: 10.1016/j.cub.2012.07.005

Deng, P., Muhammad, S., Cao, M., and Wu, L. (2018). Biogenesis and regulatory hierarchy of phased small interfering RNAs in plants. Plant Biotechnol. J. 16, 965-975. doi: 10.1111/pbi.12882

Ding, Y., Tao, Y., and Zhu, C. (2013). Emerging roles of microRNAs in the mediation of drought stress response in plants. J. Exp. Bot. 64, 3077-3086. doi: $10.1093 /$ jxb/ert164

Du, F., Gong, W., Bosca, S., Tucker, M., and Vaucheret, H. (2020). Dosedependent AGO1-mediated inhibition of the miRNA165/166 pathway modulates stem cell maintenance in arabidopsis shoot apical meristem. Plant Commun. 1:100002. doi: 10.1016/j.xplc.2019.100002

$\mathrm{Du}$, Q., and Wang, H. (2015). The role of HD-ZIP III transcription factors and miR165/166 in vascular development and secondary cell wall formation. Plant Signal. Behav. 10:e1078955. doi: 10.1080/15592324.2015.1078955

Duan, C. G., Zhang, H., Tang, K., Zhu, X., and Qian, W. (2015). Specific but interdependent functions for Arabidopsis AGO4 and AGO6 in RNA-directed DNA methylation. EMBO J. 34, 581-592. doi: 10.15252/embj.201489453

Elbashir, S. M., Harborth, J., Lendeckel, W., Yalcin, A., and Weber, K. (2001). Duplexes of 21-nucleotide RNAs mediate RNA interference in cultured mammalian cells. Nature 411, 494-498. doi: 10.1038/35078107

Endo, Y., Iwakawa, H. O., and Tomari, Y. (2013). Arabidopsis ARGONAUTE7 selects miR390 through multiple checkpoints during RISC assembly. EMBO Rep. 14, 652-658. doi: 10.1038/embor.2013.73 
Fahlgren, N., Montgomery, T. A., Howell, M. D., Allen, E., and Dvorak, S. K. (2006). Regulation of AUXIN RESPONSE FACTOR3 by TAS3 ta-siRNA affects developmental timing and patterning in Arabidopsis. Curr. Biol. 16, 939-944. doi: 10.1016/j.cub.2006.03.065

Fan, S., Zhang, D., Gao, C., Wan, S., and Lei, C. (2018). Mediation of flower induction by gibberellin and its inhibitor paclobutrazol: MRNA and miRNA integration comprises complex regulatory cross-talk in apple. Plant Cell Physiol. 59, 2288-2307. doi: 10.1093/pcp/pcy154

Fang, X., and Qi, Y. (2016). RNAi in plants: an Argonaute-Centered view. Plant Cell 28, 272-285. doi: 10.1105/tpc.15.00920

Fire, A., Xu, S., Montgomery, M. K., Kostas, S. A., and Driver, S. E. (1998). Potent and specific genetic interference by double-stranded RNA in Caenorhabditis elegans. Nature 391, 806-811. doi: 10.1038/35888

Floyd, S. K., and Bowman, J. L. (2004). Gene regulation: ancient microRNA target sequences in plants. Nature 428, 485-486. doi: 10.1038/428485a

Fouracre, J. P., He, J., Chen, V. J., Sidoli, S., and Poethig, R. S. (2021). VAL genes regulate vegetative phase change via miR156-dependent and independent mechanisms. PLoS Genet. 17:e1009626. doi: 10.1371/journal.pgen.1009626

Gaillochet, C., and Lohmann, J. U. (2015). The never-ending story: From pluripotency to plant developmental plasticity. Development 142, 2237-2249. doi: 10.1242/dev.117614

Guan, X., Pang, M., Nah, G., Shi, X., and Ye, W. (2014). MiR828 and miR858 regulate homoeologous MYB2 gene functions in Arabidopsis trichome and cotton fibre development. Nat. Commun. 5:3050. doi: 10.1038/ncomms 4050

Guo, C., Jiang, Y., Shi, M., Wu, X., and Wu, G. (2021). ABI5 acts downstream of miR159 to delay vegetative phase change in Arabidopsis. New Phytol. 231, 339-350. doi: 10.1111/nph.17371

Guo, H. S., Xie, Q., Fei, J. F., and Chua, N. H. (2005). MicroRNA directs mRNA cleavage of the transcription factor NAC1 to downregulate auxin signals for arabidopsis lateral root development. Plant Cell 17, 1376-1386. doi: $10.1105 /$ tpc.105.030841

Guo, C., Xu, Y., Shi, M., Lai, Y., and Wu, X. (2017). Repression of miR156 by miR159 regulates the timing of the juvenile-to-adult transition in arabidopsis. Plant Cell 29, 1293-1304. doi: 10.1105/tpc.16.00975

Gutierrez, L., Bussell, J. D., Pacurar, D. I., Schwambach, J., and Pacurar, M. (2009). Phenotypic plasticity of adventitious rooting in Arabidopsis is controlled by complex regulation of AUXIN RESPONSE FACTOR transcripts and microRNA abundance. Plant Cell 21, 3119-3132. doi: 10.1105/tpc.108.064758

Ha, M., and Kim, V. N. (2014). Regulation of microRNA biogenesis. Nat. Rev. Mol. Cell Biol. 15, 509-524. doi: 10.1038/nrm3838

Hamilton, A. J., and Baulcombe, D. C. (1999). A species of small antisense RNA in posttranscriptional gene silencing in plants. Science 286, 950-952. doi: $10.1126 /$ science. 286.5441 .950

Han, J., Fang, J., Wang, C., Yin, Y., and Sun, X. (2014). Grapevine microRNAs responsive to exogenous gibberellin. BMC Genomics 15:111. doi: 10.1186/1471-2164-15-111

Han, M. H., Goud, S., Song, L., and Fedoroff, N. (2004). The Arabidopsis double-stranded RNA-binding protein HYL1 plays a role in microRNAmediated gene regulation. Proc. Natl. Acad. Sci. U. S. A. 101, 1093-1098. doi: 10.1073/pnas.0307969100

Hay, A., Craft, J., and Tsiantis, M. (2004). Plant hormones and homeoboxes: bridging the gap? BioEssays 26, 395-404. doi: 10.1002/bies.20016

He, J., Xu, M., Willmann, M. R., McCormick, K., and Hu, T. (2018). Thresholddependent repression of SPL gene expression by miR156/miR157 controls vegetative phase change in Arabidopsis thaliana. PLoS Genet. 14:e1007337. doi: 10.1371/journal.pgen.1007337

Hibara, K., Karim, M. R., Takada, S., Taoka, K., and Furutani, M. (2006). Arabidopsis CUP-SHAPED COTYLEDON3 regulates postembryonic shoot meristem and organ boundary formation. Plant Cell 18, 2946-2957. doi: 10.1105/tpc.106.045716

Huen, A. K., Rodriguez-Medina, C., Ho, A., Atkins, C. A., and Smith, P. (2017). Long-distance movement of phosphate starvation-responsive microRNAs in Arabidopsis. Plant Biol. 19, 643-649. doi: 10.1111/plb.12568

Ji, L., Liu, X., Yan, J., Wang, W., and Yumul, R. E. (2011). ARGONAUTE10 and ARGONAUTE1 regulate the termination of floral stem cells through two microRNAs in Arabidopsis. PLoS Genet. 7:e1001358. doi: 10.1371/journal. pgen. 1001358

Jia, X., Ding, N., Fan, W., Yan, J., and Gu, Y. (2015). Functional plasticity of miR165/166 in plant development revealed by small tandem target mimic. Plant Sci. 233, 11-21. doi: 10.1016/j.plantsci.2014.12.020
Jing, X., Rui, M., and Blake, C. (2017). The emergence, evolution, and diversification of the miR390-TAS3-ARF pathway in land plants. Plant Cell 29, 1232-1247. doi: $10.1105 /$ tpc.17.00185

Jodder, J. (2020). MiRNA-mediated regulation of auxin signaling pathway during plant development and stress responses. J. Biosci. 45:91. doi: 10.1007/ s12038-020-00062-1

Jones-Rhoades, M. W., and Bartel, D. P. (2004). Computational identification of plant microRNAs and their targets, including a stress-induced miRNA. Mol. Cell 14, 787-799. doi: 10.1016/j.molcel.2004.05.027

Jones-Rhoades, M. W., Bartel, D. P., and Bartel, B. (2006). MicroRNAS and their regulatory roles in plants. Annu. Rev. Plant Biol. 57, 19-53. doi: 10.1146/ annurev.arplant.57.032905.105218

Jung, J. H., and Park, C. M. (2007). MIR166/165 genes exhibit dynamic expression patterns in regulating shoot apical meristem and floral development in Arabidopsis. Planta 225, 1327-1338. doi: 10.1007/s00425-006-0439-1

Jung, J. H., Seo, P. J., and Park, C. M. (2009). MicroRNA biogenesis and function in higher plants. Plant Biotechnol. Rep. 3, 111-126. doi: 10.1007/ s11816-009-0085-8

Jung, J. H., Seo, Y. H., Seo, P. J., Reyes, J. L., and Yun, J. (2007). The GIGANTEAregulated microRNA172 mediates photoperiodic flowering independent of CONSTANS in Arabidopsis. Plant Cell 19, 2736-2748. doi: 10.1105/ tpc. 107.054528

Kang, J., and Dengler, N. (2002). Cell cycling frequency and expression of the homeobox gene ATHB-8 during leaf vein development in Arabidopsis. Planta 216, 212-219. doi: 10.1007/s00425-002-0847-9

Kasschau, K. D., Xie, Z., Allen, E., Llave, C., and Chapman, E. J. (2003). P1/ HC-pro, a viral suppressor of RNA silencing, interferes with Arabidopsis development and miRNA unction. Dev. Cell 4, 205-217. doi: 10.1016/ S1534-5807(03)00025-X

Kidner, C. A., and Martienssen, R. A. (2004). Spatially restricted microRNA directs leaf polarity through ARGONAUTE1. Nature 428, 81-84. doi: 10.1038/ nature 02366

Kim, V. N. (2005). Small RNAs: classification, biogenesis, and function. Mol. Cells 19, 1-15.

Kim, J. H., Choi, D., and Kende, H. (2003). The AtGRF family of putative transcription factors is involved in leaf and cotyledon growth in Arabidopsis. Plant J. 36, 94-104. doi: 10.1046/j.1365-313X.2003.01862.x

Kim, J., Jung, J. H., Reyes, J. L., Kim, Y. S., and Kim, S. Y. (2005). MicroRNAdirected cleavage of ATHB15 mRNA regulates vascular development in Arabidopsis inflorescence stems. Plant J. 42, 84-94. doi: 10.1111/j.1365-313X.2005.02354.x

Kim, J. J., Lee, J. H., Kim, W., Jung, H. S., and Huijser, P. (2012). The microRNA156-SQUAMOSA PROMOTER BINDING PROTEIN-LIKE3 module regulates ambient temperature-responsive flowering via FLOWERING LOCUS T in Arabidopsis. Plant Physiol. 159, 461-478. doi: 10.1104/ pp.111.192369

Kim, S., Yang, J. Y., Xu, J., Jang, I. C., and Prigge, M. J. (2008). Two capbinding proteins $\mathrm{CBP} 20$ and $\mathrm{CBP} 80$ are involved in processing primary MicroRNAs. Plant Cell Physiol. 49, 1634-1644. doi: 10.1093/pcp/pcn146

Knauer, S., Holt, A. L., Rubio-Somoza, I., Tucker, E. J., and Hinze, A. (2013). A protodermal miR394 signal defines a region of stem cell competence in the Arabidopsis shoot meristem. Dev. Cell 24, 125-132. doi: 10.1016/j. devcel.2012.12.009

Koyama, T., Mitsuda, N., Seki, M., Shinozaki, K., and Ohme-Takagi, M. (2010). TCP transcription factors regulate the activities of ASYMMETRIC LEAVES1 and miR164, as well as the auxin response, during differentiation of LEAVES in Arabidopsis. Plant Cell 22, 3574-3588. doi: 10.1105/tpc.110.075598

Koyama, T., Sato, F., and Ohme-Takagi, M. (2017). Roles of miR319 and TCP transcription factors in leaf development. Plant Physiol. 175, 874-885. doi: 10.1104/pp.17.00732

Kumar, A., Gautam, V., Kumar, P., Mukherjee, S., and Verma, S. (2019). Identification and co-evolution pattern of stem cell regulator miR394s and their targets among diverse plant species. BMC Evol. Biol. 19:55. doi: 10.1186/ s12862-019-1382-7

Kurihara, Y., and Watanabe, Y. (2004). Arabidopsis micro-RNA biogenesis through Dicer-like 1 protein functions. Proc. Natl. Acad. Sci. U. S. A. 101, 12753-12758. doi: 10.1073/pnas.0403115101

Kutter, C., Schob, H., Stadler, M., Meins, F. J., and Si-Ammour, A. (2007). MicroRNA-mediated regulation of stomatal development in Arabidopsis. Plant Cell 19, 2417-2429. doi: 10.1105/tpc.107.050377 
Laufs, P., Peaucelle, A., Morin, H., and Traas, J. (2004). MicroRNA regulation of the CUC genes is required for boundary size control in Arabidopsis meristems. Development 131, 4311-4322. doi: 10.1242/dev.01320

Lauter, N., Kampani, A., Carlson, S., Goebel, M., and Moose, S. P. (2005). MicroRNA172 down-regulates glossy15 to promote vegetative phase change in maize. Proc. Natl. Acad. Sci. U. S. A. 102, 9412-9417. doi: 10.1073/pnas.0503927102

Lee, R. C., Feinbaum, R. L., and Ambros, V. (1993). The C. Elegans heterochronic gene lin-4 encodes small RNAs with antisense complementarity to lin-14. Cell 75, 843-854. doi: 10.1016/0092-8674(93)90529-Y

Lee, Y., Kim, M., Han, J., Yeom, K. H., and Lee, S. (2004). MicroRNA genes are transcribed by RNA polymerase II. EMBO J. 23, 4051-4060. doi: 10.1038/ sj.emboj.7600385

Leng, X., Wang, P., Zhu, X., Li, X., and Zheng, T. (2017). Ectopic expression of CSD1 and CSD2 targeting genes of miR398 in grapevine is associated with oxidative stress tolerance. Funct. Integr. Genomics 17, 697-710. doi: 10.1007/s10142-017-0565-9

Li, W., Cui, X., Meng, Z., Huang, X., and Xie, Q. (2012). Transcriptional regulation of Arabidopsis MIR168a and argonautel homeostasis in abscisic acid and abiotic stress responses. Plant Physiol. 158, 1279-1292. doi: 10.1104/ pp.111.188789

Li, T., Gonzalez, N., Inze, D., and Dubois, M. (2020). Emerging connections between small RNAs and Phytohormones. Trends Plant Sci. 25, 912-929. doi: $10.1016 /$ j.tplants.2020.04.004

Li, W. X., Oono, Y., Zhu, J., He, X. J., and Wu, J. M. (2008). The Arabidopsis NFYA5 transcription factor is regulated transcriptionally and posttranscriptionally to promote drought resistance. Plant Cell 20, 2238-2251. doi: 10.1105/tpc.108.059444

Li, Z., Peng, J., Wen, X., and Guo, H. (2013). Ethylene-insensitive3 is a senescence-associated gene that accelerates age-dependent leaf senescence by directly repressing miR164 transcription in Arabidopsis. Plant Cell 25, 3311-3328. doi: 10.1105/tpc.113.113340

Li, X., Qian, Q., Fu, Z., Wang, Y., and Xiong, G. (2003). Control of tillering in rice. Nature 422, 618-621. doi: 10.1038/nature01518

Li, Y., Tong, Y., He, X., Zhu, Y., and Wang, W. (2021). The rice miR171bSCL6-IIs module controls blast resistance, grain yield, and flowering. Crop J. doi: 10.1016/j.cj.2021.05.004, Epub ahead of print

Li, J., Yang, Z., Yu, B., Liu, J., and Chen, X. (2005). Methylation protects miRNAs and siRNAs from a $3^{\prime}$-end uridylation activity in Arabidopsis. Curr. Biol. 15, 1501-1507. doi: 10.1016/j.cub.2005.07.029

Lian, H., Wang, L., Ma, N., Zhou, C. M., and Han, L. (2021). Redundant and specific roles of individual MIR172 genes in plant development. PLoS Biol. 19:e3001044. doi: 10.1371/journal.pbio.3001044

Liebsch, D., and Palatnik, J. F. (2020). MicroRNA miR396, GRF transcription factors and GIF co-regulators: A conserved plant growth regulatory module with potential for breeding and biotechnology. Curr. Opin. Plant Biol. 53, 31-42. doi: 10.1016/j.pbi.2019.09.008

Lin, S. I., Chiang, S. F., Lin, W. Y., Chen, J. W., Tseng, C. Y., Wu, P. C., et al. (2008). Regulatory network of microRNA399 and PHO2 by systemic signaling. Plant Physiol. 147, 732-746. doi: 10.1104/pp.108.116269

Liu, H., Guo, S., Xu, Y., Li, C., and Zhang, Z. (2014a). OsmiR396d-regulated OsGRFs function in floral organogenesis in rice through binding to their targets OsJMJ706 and OsCR4. Plant Physiol. 165, 160-174. doi: 10.1104/ pp.114.235564

Liu, H., Jia, S., Shen, D., Liu, J., and Li, J. (2012). Four AUXIN RESPONSE FACTOR genes downregulated by microRNA167 are associated with growth and development in Oryza sativa. Funct. Plant Biol. 39, 736-744. doi: 10.1071/ FP12106

Liu, B., Li, J., Tsykin, A., Liu, L., and Gaur, A. B. (2009a). Exploring complex miRNA-mRNA interactions with Bayesian networks by splitting-averaging strategy. BMC Bioinformatics 10:408. doi: 10.1186/1471-2105-10-408

Liu, Z., Li, J., Wang, L., Li, Q., and Lu, Q. (2016). Repression of callus initiation by the miRNA-directed interaction of auxin-cytokinin in Arabidopsis thaliana. Plant J. 87, 391-402. doi: 10.1111/tpj.13211

Liu, P. P., Montgomery, T. A., Fahlgren, N., Kasschau, K. D., and Nonogaki, H. (2007). Repression of AUXIN RESPONSE FACTOR10 by microRNA160 is critical for seed germination and post-germination stages. Plant J. 52, 133-146. doi: 10.1111/j.1365-313X.2007.03218.x

Liu, D., Song, Y., Chen, Z., and Yu, D. (2009b). Ectopic expression of miR396 suppresses GRF target gene expression and alters leaf growth in Arabidopsis. Physiol. Plant. 136, 223-236. doi: 10.1111/j.1399-3054.2009.01229.x
Liu, N., Wu, S., Van Houten, J., Wang, Y., and Ding, B. (2014b). Downregulation of AUXIN RESPONSE FACTORS 6 and 8 by microRNA 167 leads to floral development defects and female sterility in tomato. J. Exp. Bot. 65, 2507-2520. doi: 10.1093/jxb/eru141

Liu, Q., Yao, X., Pi, L., Wang, H., and Cui, X. (2009c). The ARGONAUTE10 gene modulates shoot apical meristem maintenance and establishment of leaf polarity by repressing miR165/166 in Arabidopsis. Plant J. 58, 27-40. doi: 10.1111/j.1365-313X.2008.03757.x

Llave, C., Xie, Z., Kasschau, K. D., and Carrington, J. C. (2002). Cleavage of scarecrow-like mRNA targets directed by a class of Arabidopsis miRNA. Science 297, 2053-2056. doi: 10.1126/science.1076311

Lopez-Ruiz, B. A., Juarez-Gonzalez, V. T., Sandoval-Zapotitla, E., and Dinkova, T. D. (2019). Development-related miRNA expression and target regulation during staggered in vitro plant regeneration of tuxpeno VS-535 maize cultivar. Int. J. Mol. Sci. 20:2079. doi: 10.3390/ijms20092079

Lu, Y., Feng, Z., Liu, X., Bian, L., and Xie, H. (2018). MiR393 and miR390 synergistically regulate lateral root growth in rice under different conditions. BMC Plant Biol. 18:261. doi: 10.1186/s12870-018-1488-x

Ma, Z., Hu, X., Cai, W., Huang, W., and Zhou, X. (2014). Arabidopsis miR171targeted scarecrow-like proteins bind to GT cis-elements and mediate gibberellin-regulated chlorophyll biosynthesis under light conditions. PLoS Genet. 10:e1004519. doi: 10.1371/journal.pgen.1004519

Ma, J., Zhao, P., Liu, S., Yang, Q., and Guo, H. (2020). The control of developmental phase transitions by microRNAs and their targets in seed plants. Int. J. Mol. Sci. 21:1917. doi: 10.3390/ijms21061971

Mallory, A. C., Bartel, D. P., and Bartel, B. (2005). MicroRNA-directed regulation of Arabidopsis AUXIN RESPONSE FACTOR17 is essential for proper development and modulates expression of early auxin response genes. Plant Cell 17, 1360-1375. doi: 10.1105/tpc.105.031716

Manuela, D., and Xu, M. (2020). Patterning a leaf by establishing polarities. Front. Plant Sci. 11:568730. doi: 10.3389/fpls.2020.568730

Marin, E., Jounnet, V., Herz, A., Lokerse, A. S., and Weijers, D. (2010). MiR390, Arabidopsis TAS3 tasiRNAs, and their AUXIN RESPONSE FACTOR targets define an autoregulatory network quantitatively regulating lateral root growth. Plant Cell 22, 1104-1117. doi: 10.1105/tpc.109.072553

Martin, A., Adam, H., Diaz-Mendoza, M., Zurczak, M., and Gonzalez-Schain, N. D. (2009). Graft-transmissible induction of potato tuberization by the microRNA miR172. Development 136, 2873-2881. doi: 10.1242/dev.031658

Melnyk, C. W., Molnar, A., and Baulcombe, D. C. (2011). Intercellular and systemic movement of RNA silencing signals. EMBO J. 30, 3553-3563. doi: 10.1038/emboj.2011.274

Merelo, P., Ram, H., Pia, C. M., Ohno, C., and Ott, F. (2016). Regulation of MIR165/166 by class II and class III homeodomain leucine zipper proteins establishes leaf polarity. Proc. Natl. Acad. Sci. U. S. A. 113, 11973-11978. doi: 10.1073/pnas.1516110113

Millar, A. A., and Gubler, F. (2005). The Arabidopsis GAMYB-like genes, MYB33 and MYB65, are microRNA-regulated genes that redundantly facilitate anther development. Plant Cell 17, 705-721. doi: 10.1105/tpc.104.027920

Millar, A. A., Lohe, A., and Wong, G. (2019). Biology and function of miR159 in plants. Plan. Theory 8:255. doi: 10.3390/plants8080255

Montgomery, T. A., Howell, M. D., Cuperus, J. T., Li, D., and Hansen, J. E. (2008). Specificity of ARGONAUTE7-miR390 interaction and dual functionality in TAS3 trans-acting siRNA formation. Cell 133, 128-141. doi: 10.1016/j.cell.2008.02.033

Muller, C. J., Valdes, A. E., Wang, G., Ramachandran, P., and Beste, L. (2016). PHABULOSA mediates an auxin signaling loop to regulate vascular patterning in arabidopsis. Plant Physiol. 170, 956-970. doi: 10.1104/pp.15.01204

Muraro, D., Mellor, N., Pound, M. P., Help, H., and Lucas, M. (2014). Integration of hormonal signaling networks and mobile microRNAs is required for vascular patterning in Arabidopsis roots. Proc. Natl. Acad. Sci. U. S. A. 111, 857-862. doi: 10.1073/pnas.1221766111

Nair, S. K., Wang, N., Turuspekov, Y., Pourkheirandish, M., and Sinsuwongwat, S. (2010). Cleistogamous flowering in barley arises from the suppression of microRNA-guided HvAP2 mRNA cleavage. Proc. Natl. Acad. Sci. U. S. A. 107, 490-495. doi: 10.1073/pnas.0909097107

Naqvi, A. R., Sarwat, M., Hasan, S., and Roychodhury, N. (2012). Biogenesis, functions and fate of plant microRNAs. J. Cell. Physiol. 227, 3163-3168. doi: $10.1002 /$ jcp. 24052

O’Brien, J., Hayder, H., Zayed, Y., and Peng, C. (2018). Overview of MicroRNA biogenesis, mechanisms of actions, and circulation. Front. Endocrinol. 9:402. doi: $10.3389 /$ fendo.2018.00402 
Ori, N., Cohen, A. R., Etzioni, A., Brand, A., and Yanai, O. (2007). Regulation of LANCEOLATE by miR319 is required for compound-leaf development in tomato. Nat. Genet. 39, 787-791. doi: 10.1038/ng2036

Palatnik, J. F., Wollmann, H., Schommer, C., Schwab, R., and Boisbouvier, J. (2007). Sequence and expression differences underlie functional specialization of Arabidopsis microRNAs miR159 and miR319. Dev. Cell 13, 115-125. doi: 10.1016/j.devcel.2007.04.012

Pal-Bhadra, M., Bhadra, U., and Birchler, J. A. (2002). RNAi related mechanisms affect both transcriptional and posttranscriptional transgene silencing in drosophila. Mol. Cell 9, 315-327. doi: 10.1016/S1097-2765(02)00440-9

Pant, B. D, Buhtz, A., Kehr, J., and Scheible, W. R. (2008). MicroRNA399 is a long-distance signal for the regulation of plant phosphate homeostasis. Plant J. 53, 731-738. doi: 10.1111/j.1365-313X.2007.03363.x

Park, M. Y., Wu, G., Gonzalez-Sulser, A., Vaucheret, H., and Poethig, R. S. (2005). Nuclear processing and export of microRNAs in Arabidopsis. Proc. Natl. Acad. Sci. U. S. A. 102, 3691-3696. doi: 10.1073/pnas. 0405570102

Parry, G., Calderon-Villalobos, L. I., Prigge, M., Peret, B., and Dharmasiri, S. (2009). Complex regulation of the TIR1/AFB family of auxin receptors. Proc. Natl. Acad. Sci. U. S. A. 106, 22540-22545. doi: 10.1073/pnas.0911967106

Piazza, P., Jasinski, S., and Tsiantis, M. (2005). Evolution of leaf developmental mechanisms. New Phytol. 167, 693-710. doi: 10.1111/j.1469-8137.2005.01466.x

Qi, Y., Denli, A. M., and Hannon, G. J. (2005). Biochemical specialization within Arabidopsis RNA silencing pathways. Mol. Cell 19, 421-428. doi: 10.1016/j.molcel.2005.06.014

Qi, Y., He, X., Wang, X. J., Kohany, O., and Jurka, J. (2006). Distinct catalytic and non-catalytic roles of ARGONAUTE4 in RNA-directed DNA methylation. Nature 443, 1008-1012. doi: 10.1038/nature05198

Qu, L., Lin, L. B., and Xue, H. W. (2019). Rice miR394 suppresses LEAF inclination through targeting an F-box gene, LEAF INCLINATION 4. J. Integr. Plant Biol. 61, 406-416. doi: 10.1111/jipb.12713

Ramachandran, P., Carlsbecker, A., and Etchells, J. P. (2017). Class III HD-ZIPs govern vascular cell fate: An HD view on patterning and differentiation. J. Exp. Bot. 68, 55-69. doi: 10.1093/jxb/erw370

Raman, S., Greb, T., Peaucelle, A., Blein, T., and Laufs, P. (2008). Interplay of miR164, CUP-SHAPED COTYLEDON genes and LATERAL SUPPRESSOR controls axillary meristem formation in Arabidopsis thaliana. Plant J. 55, 65-76. doi: 10.1111/j.1365-313X.2008.03483.x

Rodriguez, R. E., Mecchia, M. A., Debernardi, J. M., Schommer, C., and Weigel, D. (2010). Control of cell proliferation in Arabidopsis thaliana by microRNA miR396. Development 137, 103-112. doi: 10.1242/dev.043067

Ru, P., Xu, L., Ma, H., and Huang, H. (2006). Plant fertility defects induced by the enhanced expression of microRNA167. Cell Res. 16, 457-465. doi: $10.1038 /$ sj.cr.7310057

Rubio-Somoza, I., and Weigel, D. (2013). Coordination of flower maturation by a regulatory circuit of three microRNAs. PLoS Genet. 9:e1003374. doi: 10.1371/journal.pgen.1003374

Salvi, S., Sponza, G., Morgante, M., Tomes, D., and Niu, X. (2007). Conserved noncoding genomic sequences associated with a flowering-time quantitative trait locus in maize. Proc. Natl. Acad. Sci. U. S. A. 104, 11376-11381. doi: 10.1073/pnas.0704145104

Schommer, C., Debernardi, J. M., Bresso, E. G., Rodriguez, R. E., and Palatnik, J. F. (2014). Repression of cell proliferation by miR319-regulated TCP4. Mol. Plant 7, 1533-1544. doi: $10.1093 / \mathrm{mp} / \mathrm{ssu} 084$

Schoof, H., Lenhard, M., Haecker, A., Mayer, K. F., and Jurgens, G. (2000). The stem cell population of Arabidopsis shoot meristems in maintained by a regulatory loop between the CLAVATA and WUSCHEL genes. Cell 100, 635-644. doi: 10.1016/S0092-8674(00)80700-X

Schwab, R., Palatnik, J. F., Riester, M., Schommer, C., and Schmid, M. (2005). Specific effects of microRNAs on the plant transcriptome. Dev. Cell 8, 517-527. doi: 10.1016/j.devcel.2005.01.018

Scofield, S., Dewitte, W., and Murray, J. A. (2014). STM sustains stem cell function in the Arabidopsis shoot apical meristem and controls KNOX gene expression independently of the transcriptional repressor AS1. Plant Signal. Behav. 9:e28934. doi: 10.4161/psb.28934

Sijen, T., Vijn, I., Rebocho, A., van Blokland, R., and Roelofs, D. (2001). Transcriptional and posttranscriptional gene silencing are mechanistically related. Curr. Biol. 11, 436-440. doi: 10.1016/S0960-9822(01) 00116-6
Singh, R. K., Gase, K., Baldwin, I. T., and Pandey, S. P. (2015). Molecular evolution and diversification of the Argonaute family of proteins in plants. BMC Plant Biol. 15:23. doi: 10.1186/s12870-014-0364-6

Skopelitis, D. S., Benkovics, A. H., Husbands, A. Y., and Timmermans, M. (2017). Boundary formation through a direct threshold-based readout of mobile small RNA gradients. Dev. Cell 43, 265-273. doi: 10.1016/j. devcel.2017.10.003

Skopelitis, D. S., Hill, K., Klesen, S., Marco, C. F., and von Born, P. (2018). Gating of miRNA movement at defined cell-cell interfaces governs their impact as positional signals. Nat. Commun. 9:3107. doi: 10.1038/s41467-018-05571-0

Somssich, M., Je, B. I., Simon, R., and Jackson, D. (2016). CLAVATA-WUSCHEL signaling in the shoot meristem. Development 143, 3238-3248. doi: 10.1242/ dev. 133645

Song, J. B., Huang, S. Q., Dalmay, T., and Yang, Z. M. (2012). Regulation of LEAF morphology by microRNA394 and its target LEAF CURLING RESPONSIVENESS. Plant Cell Physiol. 53, 1283-1294. doi: 10.1093/pcp/ pcs080

Song, X., Li, Y., Cao, X., and Qi, Y. (2019). MicroRNAs and their regulatory roles in plant-environment interactions. Annu. Rev. Plant Biol. 70, 489-525. doi: 10.1146/annurev-arplant-050718-100334

Sorin, C., Declerck, M., Christ, A., Blein, T., and Ma, L. (2014). A miR169 isoform regulates specific NF-YA targets and root architecture in Arabidopsis. New Phytol. 202, 1197-1211. doi: 10.1111/nph.12735

Stricklin, S. L., Griffiths-Jones, S., and Eddy, S. R. (2005). C. Elegans noncoding RNA genes. WormBook 25, 1-7. doi: 10.1895/wormbook.1.1.1

Su, Z., Wang, N., Hou, Z., Li, B., and Li, D. (2020). Regulation of female germline specification via small RNA mobility in arabidopsis. Plant Cell 32, 2842-2854. doi: 10.1105/tpc.20.00126

Sun, Z., Li, M., Zhou, Y., Guo, T., and Liu, Y. (2018). Coordinated regulation of Arabidopsis microRNA biogenesis and red light signaling through Dicerlike 1 and phytochrome-interacting factor 4. PLoS Genet. 14:e1007247. doi: 10.1371/journal.pgen.1007247

Sun, X., Wang, C., Xiang, N., Li, X., and Yang, S. (2017). Activation of secondary cell wall biosynthesis by miR319-targeted TCP4 transcription factor. Plant Biotechnol. J. 15, 1284-1294. doi: 10.1111/pbi.12715

Sunkar, R., and Zhu, J. K. (2004). Novel and stress-regulated microRNAs and other small RNAs from Arabidopsis. Plant Cell 16, 2001-2019. doi: 10.1105/ tpc. 104.022830

Szczygiel-Sommer, A., and Gaj, M. D. (2019). The miR396-GRF regulatory module controls the embryogenic response in arabidopsis via an auxin-related pathway. Int. J. Mol. Sci. 20:5221. doi: 10.3390/ijms 20205221

Tamiru, M., Hardcastle, T. J., and Lewsey, M. G. (2018). Regulation of genomewide DNA methylation by mobile small RNAs. New Phytol. 217, 540-546. doi: $10.1111 / \mathrm{nph} .14874$

Tang, G., Yan, J., Gu, Y., Qiao, M., and Fan, R. (2012). Construction of short tandem target mimic (STTM) to block the functions of plant and animal microRNAs. Methods 58, 118-125. doi: 10.1016/j.ymeth.2012. 10.006

Tatematsu, K., Toyokura, K., and Okada, K. (2015). Requirement of MIR165A primary transcript sequence for its activity pattern in Arabidopsis leaf primordia. Plant Signal. Behav. 10:e1055432. doi: 10.1080/15592324.2015. 1055432

Tirumalai, V., Swetha, C., Nair, A., Pandit, A., and Shivaprasad, P. V. (2019). MiR828 and miR858 regulate VvMYB114 to promote anthocyanin and flavonol accumulation in grapes. J. Exp. Bot. 70, 4775-4792. doi: 10.1093/ jxb/erz264

Tsikou, D., Yan, Z., Holt, D. B., Abel, N. B., and Reid, D. E. (2018). Systemic control of legume susceptibility to rhizobial infection by a mobile microRNA. Science 362, 233-236. doi: 10.1126/science.aat6907

Tsuji, H., Aya, K., Ueguchi-Tanaka, M., Shimada, Y., and Nakazono, M. (2006). GAMYB controls different sets of genes and is differentially regulated by microRNA in aleurone cells and anthers. Plant J. 47, 427-444. doi: 10.1111/j. 1365-313X.2006.02795.x

Vaten, A., Dettmer, J., Wu, S., Stierhof, Y. D., and Miyashima, S. (2011). Callose biosynthesis regulates symplastic trafficking during root development. Dev. Cell 21, 1144-1155. doi: 10.1016/j.devcel.2011.10.006

Vaucheret, H. (2008). Plant ARGONAUTES. Trends Plant Sci. 13, 350-358. doi: $10.1016 /$ j.tplants.2008.04.007 
Veit, B. (2009). Hormone mediated regulation of the shoot apical meristem. Plant Mol. Biol. 69, 397-408. doi: 10.1007/s11103-008-9396-3

Voinnet, O. (2009). Origin, biogenesis, and activity of plant microRNAs. Cell 136, 669-687. doi: 10.1016/j.cell.2009.01.046

Waheed, S., and Zeng, L. (2020). The critical role of miRNAs in regulation of flowering time and flower development. Genes 11:319. doi: 10.3390/ genes 11030319

Wang, J., Bao, J., Zhou, B., Li, M., and Li, X. (2021b). The Osa-miR164 target OsCUC1 functions redundantly with OsCUC3 in controlling rice meristem/ organ boundary specification. New Phytol. 229, 1566-1581. doi: 10.1111/ nph.16939

Wang, L., Gu, X., Xu, D., Wang, W., and Wang, H. (2011). MiR396-targeted AtGRF transcription factors are required for coordination of cell division and differentiation during leaf development in Arabidopsis. J. Exp. Bot. 62, 761-773. doi: $10.1093 /$ jxb/erq307

Wang, J. J., and Guo, H. S. (2015). Cleavage of INDOLE-3-ACETIC ACID INDUCIBLE28 mRNA by microRNA847 upregulates auxin signaling to modulate cell proliferation and lateral organ growth in Arabidopsis. Plant Cell 27, 574-590. doi: 10.1105/tpc.15.00101

Wang, H., Li, Y., Chern, M., Zhu, Y., and Zhang, L. L. (2021a). Suppression of rice miR168 improves yield, flowering time and immunity. Nat. Plants 7, 129-136. doi: 10.1038/s41477-021-00852-x

Wang, L., Liu, Z., Qiao, M., and Xiang, F. (2018). MiR393 inhibits in vitro shoot regeneration in Arabidopsis thaliana via repressing TIR1. Plant Sci. 266, 1-8. doi: 10.1016/j.plantsci.2017.10.009

Wang, J. W., Schwab, R., Czech, B., Mica, E., and Weigel, D. (2008). Dual effects of miR156-targeted SPL genes and CYP78A5/KLUH on plastochron length and organ size in Arabidopsis thaliana. Plant Cell 20, 1231-1243. doi: $10.1105 /$ tpc. 108.058180

Wang, H., and Wang, H. (2015). The miR156/SPL module, a regulatory hub and versatile toolbox, gears up crops for enhanced agronomic traits. Mol. Plant 8, 677-688. doi: 10.1016/j.molp.2015.01.008

Wang, J. W., Wang, L. J., Mao, Y. B., Cai, W. J., and Xue, H. W. (2005). Control of root cap formation by MicroRNA-targeted auxin response factors in Arabidopsis. Plant Cell 17, 2204-2216. doi: 10.1105/tpc.105. 033076

Wang, R., Yang, X., Guo, S., Wang, Z., and Zhang, Z. (2021c). MiR319-targeted OsTCP21 and OsGAmyb regulate tillering and grain yield in rice. J. Integr. Plant Biol. 63, 1260-1272. doi: 10.1111/jipb.13097

Wang, T., Zheng, Y., Tang, Q., Zhong, S., and Su, W. (2021d). Brassinosteroids inhibit miRNA-mediated translational repression by decreasing AGO1 on the endoplasmic reticulum. J. Integr. Plant Biol. 63, 1475-1490. doi: 10.1111/ jipb.13139

Werner, S., Bartrina, I., and Schmulling, T. (2021). Cytokinin regulates vegetative phase change in Arabidopsis thaliana through the miR172/TOE1-TOE2 module. Nat. Commun. 12:5816. doi: 10.1038/s41467-021-26088-z

Wightman, B., Ha, I., and Ruvkun, G. (1993). Posttranscriptional regulation of the heterochronic gene lin-14 by lin- 4 mediates temporal pattern formation in C Elegans. Cell 75, 855-862. doi: 10.1016/0092-8674(93) 90530-4

Williams, L., Grigg, S. P., Xie, M., Christensen, S., and Fletcher, J. C. (2005). Regulation of Arabidopsis shoot apical meristem and lateral organ formation by microRNA miR166g and its AtHD-ZIP target genes. Development 132, 3657-3668. doi: 10.1242/dev.01942

Windels, D., and Vazquez, F. (2011). MiR393: integrator of environmental cues in auxin signaling? Plant Signal. Behav. 6, 1672-1675. doi: 10.4161/ psb.6.11.17900

Wollmann, H., Mica, E., Todesco, M., Long, J. A., and Weigel, D. (2010). On reconciling the interactions between APETALA2, miR172 and AGAMOUS with the ABC model of flower development. Development 137, 3633-3642. doi: $10.1242 /$ dev. 036673

Wu, G., Park, M. Y., Conway, S. R., Wang, J. W., and Weigel, D. (2009). The sequential action of miR156 and miR172 regulates developmental timing in Arabidopsis. Cell 138, 750-759. doi: 10.1016/j.cell.2009.06.031

Wu, G., and Poethig, R. S. (2006). Temporal regulation of shoot development in Arabidopsis thaliana by miR156 and its target SPL3. Development 133, 3539-3547. doi: 10.1242/dev.02521

Wu, M. F., Tian, Q., and Reed, J. W. (2006). Arabidopsis microRNA167 controls patterns of ARF6 and ARF8 expression, and regulates both female and male reproduction. Development 133, 4211-4218. doi: 10.1242/ dev.02602

Xia, R., Xu, J., and Meyers, B. C. (2017). The emergence, evolution, and diversification of the miR390-TAS3-ARF pathway in land plants. Plant Cell 29, 1232-1247. doi: $10.1105 /$ tpc. 17.00185

Xie, K., Wu, C., and Xiong, L. (2006). Genomic organization, differential expression, and interaction of SQUAMOSA promoter-binding-like transcription factors and microRNA156 in rice. Plant Physiol. 142, 280-293. doi: 10.1104/ pp. 106.084475

Xing, L., Zhu, M., Luan, M., Zhang, M., and Jin, L. (2021). MiR169q and NUCLEAR FACTOR YA8 enhance salt tolerance by activating PEROXIDASE1 expression in response to ROS. Plant Physiol. 188, 608-623. doi: 10.1093/ plphys/kiab498

Xu, M., Hu, T., Smith, M. R., and Poethig, R. S. (2016a). Epigenetic regulation of vegetative phase change in arabidopsis. Plant Cell 28, 28-41. doi: 10.1105/ tpc. 15.00854

Xu, M., Hu, T., Zhao, J., Park, M. Y., and Earley, K. W. (2016b). Developmental functions of miR156-regulated SQUAMOSA PROMOTER BINDING PROTEIN-LIKE (SPL) genes in Arabidopsis thaliana. PLoS Genet. 12:e1006263. doi: 10.1371/journal.pgen.1006263

Xu, M. Y., Zhang, L., Li, W. W., Hu, X. L., and Wang, M. B. (2014). Stressinduced early flowering is mediated by miR169 in Arabidopsis thaliana. J. Exp. Bot. 65, 89-101. doi: 10.1093/jxb/ert353

Yadav, A., Kumar, S., Verma, R., Lata, C., and Sanyal, I. (2021). MicroRNA 166: An evolutionarily conserved stress biomarker in land plants targeting HD-ZIP family. Physiol. Mol. Biol. Plants 27, 2471-2485. doi: 10.1007/ s12298-021-01096-x

Yan, J., Wang, P., Wang, B., Hsu, C. C., and Tang, K. (2017). The SnRK2 kinases modulate miRNA accumulation in Arabidopsis. PLoS Genet. 13:e1006753. doi: 10.1371/journal.pgen.1006753

Yan, J., Zhao, C., Zhou, J., Yang, Y., and Wang, P. (2016). The miR165/166 mediated regulatory module plays critical roles in ABA homeostasis and response in Arabidopsis thaliana. PLoS Genet. 12:e1006416. doi: 10.1371/ journal.pgen.1006416

Yanai, O., Shani, E., Russ, D., and Ori, N. (2011). Gibberellin partly mediates LANCEOLATE activity in tomato. Plant J. 68, 571-582. doi: 10.1111/j.1365-313X.2011.04716.x

Yang, T., Wang, Y., Teotia, S., Wang, Z., and Shi, C. (2019). The interaction between miR160 and miR165/166 in the control of leaf development and drought tolerance in Arabidopsis. Sci. Rep. 9:2832. doi: 10.1038/ s41598-019-39397-7

Yao, X., Chen, J., Zhou, J., Yu, H., and Ge, C. (2019). An essential role for miRNA167 in maternal control of embryonic and seed development. Plant Physiol. 180, 453-464. doi: 10.1104/pp.19.00127

Yokotani, N., Nakano, R., Imanishi, S., Nagata, M., and Inaba, A. (2009). Ripeningassociated ethylene biosynthesis in tomato fruit is autocatalytically and developmentally regulated. J. Exp. Bot. 60, 3433-3442. doi: 10.1093/jxb/erp185

Yoon, E. K., Yang, J. H., Lim, J., Kim, S. H., and Kim, S. K. (2010). Auxin regulation of the microRNA390-dependent transacting small interfering RNA pathway in Arabidopsis lateral root development. Nucleic Acids Res. 38, 1382-1391. doi: 10.1093/nar/gkp1128

Yu, S., Galvao, V. C., Zhang, Y. C., Horrer, D., and Zhang, T. Q. (2012). Gibberellin regulates the Arabidopsis floral transition through miR156-targeted SQUAMOSA promoter binding-like transcription factors. Plant Cell 24, 3320-3332. doi: 10.1105/tpc.112.101014

Yu, Y., Jia, T., and Chen, X. (2017). The 'how' and 'where' of plant microRNAs. New Phytol. 216, 1002-1017. doi: 10.1111/nph.14834

Yu, S., and Wang, J. W. (2020). The crosstalk between MicroRNAs and gibberellin Signaling in plants. Plant Cell Physiol. 61, 1880-1890. doi: 10.1093/pcp/ pcaa079

Yu, L., Yu, X., Shen, R., and He, Y. (2005). HYL1 gene maintains venation and polarity of leaves. Planta 221, 231-242. doi: 10.1007/s00425-004-1439-7

Zhai, J., Jeong, D. H., De Paoli, E., Park, S., and Rosen, B. D. (2011). MicroRNAs as master regulators of the plant NB-LRR defense gene family via the production of phased, trans-acting siRNAs. Genes Dev. 25, 2540-2553. doi: 10.1101/gad.177527.111

Zhang, X., Henderson, I. R., Lu, C., Green, P. J., and Jacobsen, S. E. (2007). Role of RNA polymerase IV in plant small RNA metabolism. Proc. Natl. Acad. Sci. U. S. A. 104, 4536-4541. doi: 10.1073/pnas.0611456104 
Zhang, T. Q., Lian, H., Tang, H., Dolezal, K., and Zhou, C. M. (2015). An intrinsic microRNA timer regulates progressive decline in shoot regenerative capacity in plants. Plant Cell 27, 349-360. doi: 10.1105/tpc.114.135186

Zhang, B., Pan, X., and Stellwag, E. J. (2008). Identification of soybean microRNAs and their targets. Planta 229, 161-182. doi: 10.1007/ s00425-008-0818-x

Zhang, F., Wang, L., Lim, J. Y., Kim, T., and Pyo, Y. (2016). Phosphorylation of CBP20 links MicroRNA to root growth in the ethylene response. PLoS Genet. 12:e1006437. doi: 10.1371/journal.pgen.1006437

Zhang, Y. C., Yu, Y., Wang, C. Y., Li, Z. Y., and Liu, Q. (2013). Overexpression of microRNA OsmiR397 improves rice yield by increasing grain size and promoting panicle branching. Nat. Biotechnol. 31, 848-852. doi: 10.1038/ nbt. 2646

Zhang, H., Zhang, L., Han, J., Qian, Z., and Zhou, B. (2019). The nuclear localization signal is required for the function of squamosa promoter binding protein-like gene 9 to promote vegetative phase change in Arabidopsis. Plant Mol. Biol. 100, 571-578. doi: 10.1007/s11103-019-00863-5

Zhang, J., Zhou, Z., Bai, J., Tao, X., and Wang, L. (2020). Disruption of MIR396e and MIR396f improves rice yield under nitrogen-deficient conditions. Natl. Sci. Rev. 7, 102-112. doi: 10.1093/nsr/nwz142

Zhao, B., Ge, L., Liang, R., Li, W., and Ruan, K. (2009). Members of miR-169 family are induced by high salinity and transiently inhibit the NF-YA transcription factor. BMC Mol. Biol. 10:29. doi: 10.1186/14712199-10-29

Zhao, Y., Lin, S., Qiu, Z., Cao, D., and Wen, J. (2015). MicroRNA857 is involved in the regulation of secondary growth of vascular tissues in arabidopsis. Plant Physiol. 169, 2539-2552. doi: 10.1104/pp.15. 01011

Zhao, Y. F., Peng, T., Sun, H. Z., Teotia, S., and Wen, H. L. (2019). MiR1432OsACOT (acyl-CoA thioesterase) module determines grain yield via enhancing grain filling rate in rice. Plant Biotechnol. J. 17, 712-723. doi: 10.1111/ pbi. 13009

Zheng, L., Zhang, X., Zhang, H., Gu, Y., and Huang, X. (2019). The miR164dependent regulatory pathway in developing maize seed. Mol. Gen. Genomics. 294, 501-517. doi: 10.1007/s00438-018-1524-4

Zhong, R., and Ye, Z. H. (1999). IFL1, a gene regulating interfascicular fiber differentiation in Arabidopsis, encodes a homeodomain-leucine zipper protein. Plant Cell 11, 2139-2152. doi: 10.1105/tpc.11.11.2139
Zhong, R., and Ye, Z. H. (2004). Amphivasal vascular bundle 1, a gain-offunction mutation of the IFL1/REV gene, is associated with alterations in the polarity of leaves, stems and carpels. Plant Cell Physiol. 45, 369-385. doi: $10.1093 / \mathrm{pcp} / \mathrm{pch} 051$

Zhou, G. K., Kubo, M., Zhong, R., Demura, T., and Ye, Z. H. (2007). Overexpression of miR165 affects apical meristem formation, organ polarity establishment and vascular development in Arabidopsis. Plant Cell Physiol. 48, 391-404. doi: $10.1093 / \mathrm{pcp} / \mathrm{pcm} 008$

Zhou, X., Wang, G., Sutoh, K., Zhu, J. K., and Zhang, W. (2008). Identification of cold-inducible microRNAs in plants by transcriptome analysis. Biochim. Biophys. Acta 1779, 780-788. doi: 10.1016/j.bbagrm.2008.04.005

Zhu, Q. H., and Helliwell, C. A. (2011). Regulation of flowering time and floral patterning by miR172. J. Exp. Bot. 62, 487-495. doi: 10.1093/jxb/ erq295

Zhu, H., Hu, F., Wang, R., Zhou, X., and Sze, S. H. (2011). Arabidopsis Argonaute10 specifically sequesters miR166/165 to regulate shoot apical meristem development. Cell 145, 242-256. doi: 10.1016/j.cell.2011.03.024

Zhu, Q. H., Upadhyaya, N. M., Gubler, F., and Helliwell, C. A. (2009). Overexpression of miR172 causes loss of spikelet determinacy and floral organ abnormalities in rice (Oryza sativa). BMC Plant Biol. 9:149. doi: $10.1186 / 1471-2229-9-149$

Conflict of Interest: The authors declare that the research was conducted in the absence of any commercial or financial relationships that could be construed as a potential conflict of interest.

Publisher's Note: All claims expressed in this article are solely those of the authors and do not necessarily represent those of their affiliated organizations, or those of the publisher, the editors and the reviewers. Any product that may be evaluated in this article, or claim that may be made by its manufacturer, is not guaranteed or endorsed by the publisher.

Copyright (c) 2022 Dong, Hu and Zhang. This is an open-access article distributed under the terms of the Creative Commons Attribution License (CC BY). The use, distribution or reproduction in other forums is permitted, provided the original author(s) and the copyright owner(s) are credited and that the original publication in this journal is cited, in accordance with accepted academic practice. No use, distribution or reproduction is permitted which does not comply with these terms. 